University of San Diego

Digital USD

Fall 8-31-2017

\title{
Understanding and Optimizing Growth and Development of California Yellowtail (Seriola dorsalis) in Aquaculture Using Physiological Tools
}

Laura Schwebel

University of San Diego

Follow this and additional works at: https://digital.sandiego.edu/theses

Part of the Exercise Physiology Commons, and the Marine Biology Commons

\section{Digital USD Citation}

Schwebel, Laura, "Understanding and Optimizing Growth and Development of California Yellowtail (Seriola dorsalis) in Aquaculture Using Physiological Tools" (2017). Theses. 23.

https://digital.sandiego.edu/theses/23

This Thesis: Open Access is brought to you for free and open access by the Theses and Dissertations at Digital USD. It has been accepted for inclusion in Theses by an authorized administrator of Digital USD. For more information, please contact digital@sandiego.edu. 


\title{
UNIVERSITY OF SAN DIEGO
}

\author{
San Diego \\ Understanding and Optimizing Growth and Development of \\ California Yellowtail (Seriola dorsalis) in Aquaculture \\ Using Physiological Tools
}

A thesis submitted in partial satisfaction of the requirements for the degree of

Master of Science in Marine Science

by

Laura Nicole Schwebel

Thesis Committee

Mary Sue Lowery, Ph.D., Chair

Nicholas C. Wegner Ph.D.

Kevin Stuart, MS 
The thesis of Laura Nicole Schwebel is approved by:

Mary Sue Lowery, Ph.D., Chair

University of San Diego

Nicholas C. Wegner, Ph.D.

Southwest Fisheries Science Center

Kevin Stuart, MS

Hubbs-SeaWorld Research Institute

\author{
University of San Diego
}

San Diego

2017

ii 
(C) 2017 Laura Nicole Schwebel 


\section{ACKNOWLEDGMENTS}

I would first and foremost like to thank my committee for supporting me and shaping me into a confident and competent scientist. I have had the benefit of being challenged and encouraged, and it has stretched the limits of my knowledge and abilities, and allowed me to succeed. Thanks to Sue Lowery for so many constructive conversations to help shape this project, for lending a hand on many sampling occasions, and for being there to answer my myriad of questions, write letters of recommendation, and provide general support. She is an inspiration. Many thanks to my committee member and main editor Nick Wegner. Without his motivating comments like "only 120 edits" and "let's discuss", I certainly wouldn't be where I am today. I am so fortunate to have had his critical eye to make every sentence better. I would not be the strategic, critically-minded thinker and writer that I am without him. I am also indebted to him for finding funding for me to be able to focus on my thesis research full time, and for funding my first job as a marine scientist. I certainly would not be sitting in my office at the NOAA SWFSC right now without his help. A million thanks. Thanks also to Kevin Stuart who not only provided the hundreds of fish for this project but was also there to answer any and all questions I had about how to keep them all alive. His knowledge and expertise were certainly an asset.

I also have to thank my family who have supported me in a multitude of ways, from offering to clean my house when I was too busy, to offering to help with data entry, or simply being understanding when I was super busy and ignored them. I owe my mom some special thanks. Her life-long enthusiasm for 
learning and curious nature were a huge influence on me and attributed to my success in this endeavor. A million thanks to Tom, who brought me dinner at the lab when I would work late, who cooked dinner when I came home tired, who acted as a sounding board for hundreds of research related conversations, and who encouraged me in all my endeavors and educational pursuits over many years. You kept my head above water and always believed in me, and I can't thank you enough. I can't thank my family without mentioning my Uncle Rob. His generosity made it possible for me to attend graduate school, and although I will repay the loan, I will always be indebted to him for helping me achieve this lifechanging goal.

Special acknowledgments go to several of my coworkers at the Southwest Fisheries Science Center who provided support for many aspects of the project. Thank you to Andrew Thompson who helped me with R code and modeling. As a complete novice in this area, his patience and expertise were so appreciated, and saved me days of headaches and reading R forums online. His generosity won't be forgotten. Thanks to Patrick Appel, Kathy Swiney, Paula Sylvia, and Luis Rodriguez for their help keeping hundreds of fish alive. I couldn't have done it without their help and expertise. There were also many people who helped me sample and I'd like to especially thank Jon Walker for going above and beyond on many occasions. Thanks also to John Hyde and Russ Vetter from SWFSC, as well as Mark Drawbridge from HSWRI for their constructive conversations that helped guide me in this project. I also would be remiss not to thank all of the SWFSC 
volunteers who assisted with a variety of tasks from cleaning raceways, to handling fish, to taking pictures. They were all a huge help!

I would not be where I am without the strong support from all the USD faculty and Marine Science graduate students. They provided a supportive environment for learning things that were entirely unfamiliar to me, and helped me gain confidence as a scientist. Thanks to Thaïs and Nima specifically for helping me sample on several occasions and making it even more fun. I am so fortunate to have had such nurturing professors and fellow graduate students who always made me feel like I could achieve this goal. I will never forget the kind words, hugs, smiles, and mental breakdowns.

And last but certainly not least, I would like to thank the NOAA Office of Aquaculture for funding this work and Hubbs-SeaWorld Research Institute for donating the fish that made this work possible. Additionally, I'd like to thank the University of San Diego for their financial support.

No one achieves anything alone, and I am so fortunate to have had such an exceptional support system to help me succeed in this endeavor. Thank you. 


\section{TABLE OF CONTENTS}

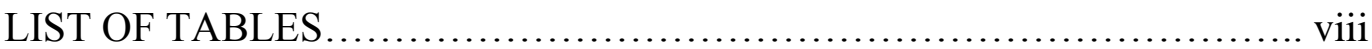

LIST OF FIGURES ...................................................

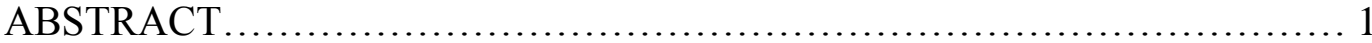

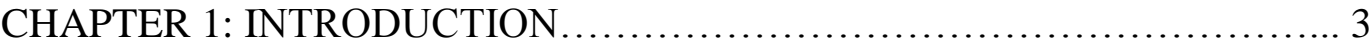

Life History of Yellowtail............................................ 3

Aquaculture overview.............................................. 4

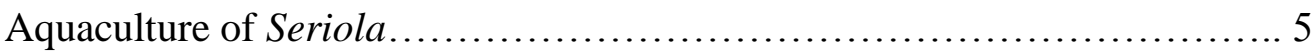

A common problem: uninflated swim bladders.......................... 7

Fish musculature.................................................. 8

Recent Seriola research............................................. 9

Metrics and goals of this thesis.................................... 11

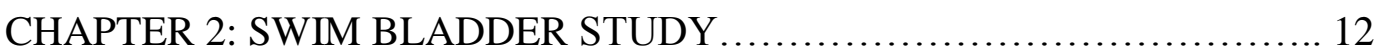

Introduction....................................................... 12

Methods.............................................................. 15

Results....................................................... 23

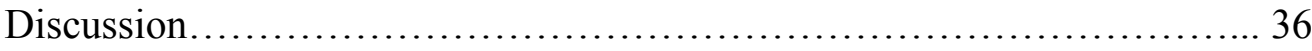

Conclusions................................................... 40

CHAPTER 3: EXERCISE STUDY ................................... 42

Introduction ...................................................... 42

Methods.......................................................... 45

Results......................................................... 60

Discussion................................................... 78

Conclusions......................................................... 84

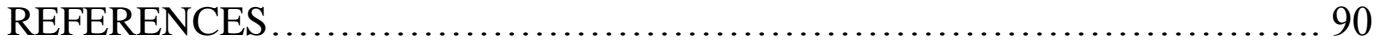




\section{LIST OF TABLES}

Table 1.1. Metrics of swimming performance for cultured S. dorsalis with properly inflated and uninflated swim bladders compared to wild-caught yellowtail. Values are group means \pm standard deviation. * Indicates significant difference of one group from the other two. ** Used to indicate significant difference between two groups.......................... 26

Table 1.2. Metrics of metabolic performance for aquaculture-reared S. dorsalis with properly inflated and uninflated swim bladders compared to wild-caught yellowtail. Mean standard metabolic rates (SMR) were adjusted to a temperature of $18^{\circ} \mathrm{C}$ using a $\mathrm{Q}_{10}=2$, and standardized to $65 \mathrm{~g}$ at Size $\mathrm{A}$, and to $410 \mathrm{~g}$ at Size B using mass ${ }^{0.80}$. Values are group means \pm standard deviation.

*Indicates significant difference of one group from the other two.......... 28

Table 2.1. Description of a priori models used to evaluate the variables $\left(L_{\infty}, t_{0}, K\right)$ for the best fit of the von Bertalanffy growth model.................... 54

Table 2.2. Final somatic measurements and FCR for each experimental group at the end of the 24-week growout period. At the start of experimentation, fish were $6.39 \pm 0.68 \mathrm{~cm} \mathrm{FL}, 7.05 \pm 0.71 \mathrm{~cm} \mathrm{BL}, 4.35 \pm 1.26 \mathrm{~g}$, and had a CF of

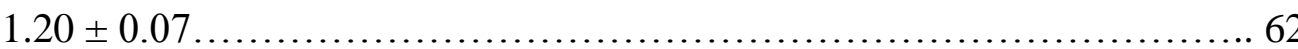

Table 2.3. Model selection results for von Bertalanffy analysis of the effect of exercise on growth of the total length of California Yellowtail (Seriola dorsalis). The chosen best-fit model based on ANOVA results and the principle of parsimony indicated in bold. 64 
Table 2.4. Estimates of von Bertalanffy growth model parameters for $S$. dorsalis subjected to continuous exercise $(2 \mathrm{~W}, 3 \mathrm{~W}, 4 \mathrm{~W})$ compared to a non-exercised control group. Standard error $(\sigma)$ included for each parameter. *Used to indicate that $4 \mathrm{~W}$ was significantly greater than the Control and $2 \mathrm{~W}$, but no other significant differences were found............................. 66

Table 2.5. Results of Welch two-sample t-tests comparing values of $\mathrm{K}$ among treatment 68

Table 2.6 Standard metabolic rate for $S$. dorsalis subjected to continuous exercise $(2 \mathrm{~W}, 3 \mathrm{~W}, 4 \mathrm{~W})$ compared to a non-exercised control group at three different sizes. For direct comparison between groups, SMR data for individual fish were adjusted to a temperature of $22{ }^{\circ} \mathrm{C}$ using $Q_{10}=2$, and scaled to $55 \mathrm{~g}$ at Size A, $205 \mathrm{~g}$ at Size B, and $410 \mathrm{~g}$ at Size C using mass ${ }^{0.80} \ldots \ldots \ldots \ldots \ldots . . . . . .70$

Table 2.7. Comparison of sustained exercise regimes and subsequent growth and FCR responses for Seriola as measured immediately following exercise.... 86

Table 2.8. SMRs of three hatchery-reared cohorts provided by HSWRI compared to a wild "standard." For direct comparison, all SMRs were adjusted to a temperature of $18^{\circ} \mathrm{C}$ using $Q_{10}=2$, and scaled to $65 \mathrm{~g}$ using mass ${ }^{0.80}$ (adjusted SMR) 88 


\section{LIST OF FIGURES}

Figure 1.1. Comparison of (A) body mass, (B) body length, $(\mathbf{C})$ girth and (D) condition factor of all groups at the start (initial) and end (final) of a 32-week growout period. Statistical significance is only shown between groups within each time point. *Indicates significant difference of one group from the other two. **Used to indicate significant difference between two groups......... 30

Figure 1.2. Metabolic rate $\left(\mathrm{M}_{2}\right)$ at various swimming speeds for wild fish (dotted line), inflated fish (grey line), and uninflated fish (black line) at (A) Size A (65 g) and approximately four months later at (B) Size B (410 g). For A, wild $n=8$, inflated $n=6$, uninflated $n=7$. For $B$, wild $n=8$, inflated $n=7$,

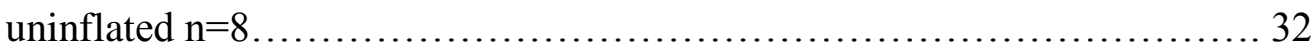

Figure 1.3. Cost of transport (COT) at (A) Size A (65 g) and approximately four months later at (B) Size B (410 g) for wild fish (dotted line), inflated fish (grey line), and uninflated fish (black line). For $\mathrm{A}$, wild $\mathrm{n}=8$, inflated $\mathrm{n}=6$, uninflated $n=7$. For $B$, wild $n=8$, inflated $n=7$, uninflated $n=8$ 34

Figure 2.1. Side view (A) and top view (B) of custom-built raceways designed for sustained exercise training...... 56

Figure 2.2. Juvenile California Yellowtail (S. dorsalis) swimming in custom-built raceways designed to encourage sustained exercise 
Figure 2.3. The percent difference in mass between each exercised group and the control over the 24-week growout period. * Indicates significant difference of that group from the control. ** Used to indicate significant difference of that

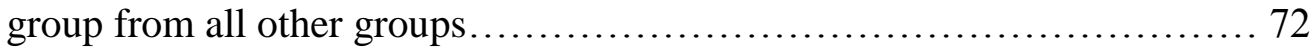

Figure 2.4. Results of the von Bertalanffy growth model fit to fork length data of each experimental group ( $\mathrm{n}=30$ for each group at each time point).

Figure 2.5. Mean standard metabolic rate (SMR) for three exercised groups (2W, $3 \mathrm{~W}$, and $4 \mathrm{~W}$ ) and a control measured at three points during growout (Size A: immediately post-exercise; Size B: approximately six weeks post-exercise; Size C: approximately 12 weeks post-post exercise). For direct comparison between groups, SMR data for individual fish were adjusted to a temperature of $22{ }^{\circ} \mathrm{C}$ using $Q_{10}=2$, and scaled to $55 \mathrm{~g}$ at Size A, $205 \mathrm{~g}$ at Size B, and $410 \mathrm{~g}$

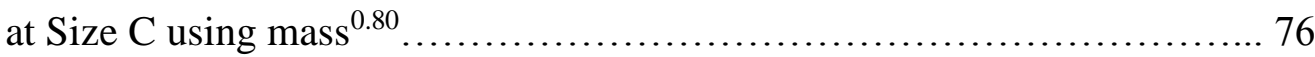




\begin{abstract}
Physical fitness metrics were used to assess the health and development of California Yellowtail, Seriola dorsalis, in an aquaculture environment during two grow-out experiments. The first experiment sought to evaluate the effects of a common aquaculture deformity (an improperly inflated swim bladder) that has been hypothesized to impact energy allocation, growth, and development. Metrics including metabolic rate, critical swimming speed, feed conversion ratio, and growth rate, were monitored over a 32-week period in three groups of California Yellowtail: wild-caught ("wild"), healthy hatchery-reared ("inflated"), and hatchery-reared with uninflated swim bladders ("uninflated"). At the start of the grow-out period, wild fish had a significantly lower standard metabolic rate (3.08 $\left.\pm 0.23 \mathrm{mgO}_{2} \mathrm{~min}^{-1} \mathrm{~kg}^{-1}\right)$ than both the inflated and uninflated groups $(5.60 \pm 0.54$ and $6.45 \pm 0.66 \mathrm{mgO}_{2} \mathrm{~min}^{-1} \mathrm{~kg}^{-1}$, respectively), but this difference was not maintained over time. After a 32-week growout, inflated fish had significantly greater mass $(758.6 \pm 92.7 \mathrm{~g}$ vs. $671.1 \pm 128.9 \mathrm{~g}$ wild, $636.1 \pm 80.4 \mathrm{~g}$ uninflated $)$ and girth $(23.2 \pm 1.1 \mathrm{~cm}$ vs. $21.6 \pm 1.7 \mathrm{~cm}$ wild, $21.5 \pm 1.2 \mathrm{~cm}$ uninflated $)$ than the other two groups, while uninflated fish had significantly shorter BL $(36.5 \pm 1.9$ cm vs. $38.4 \pm 2.7 \mathrm{~cm}$ wild, $39.6 \pm 2.0 \mathrm{~cm}$ inflated). However, the wild fish had the most efficient feed conversion (1.41 vs. 1.49 inflated, 2.08 uninflated) and needed $5.8 \%$ less feed than the inflated group, and $47.8 \%$ less feed than the uninflated group to gain equivalent mass.
\end{abstract}

In addition to indicating that it wouldn't be economical to rear yellowtail with uninflated swim bladders due to their poor growth rates and feed conversion 
ratios, the results of this experiment revealed that there is room for improvement in the fitness of healthy aquaculture-reared yellowtail by potentially lowering their metabolic rate and feed conversion ratios. The subsequent experiment introduced exercise (which is typically lacking in aquaculture) as a means for improvement of fitness in hatchery-reared fish, and aimed to determine if a short duration of exercise could have lasting effects on the fitness of cultured yellowtail. Fish were forced to swim continuously against a flow in custom designed raceways for two, three, or four weeks, following which, metabolic rate, growth rate, and feed conversion were assessed over a 24-week grow-out period. Results showed that the duration of exercise may have an impact on standard metabolic rate immediately following exercise, with the exercised groups showing about a 9-15\% reduction in metabolic rate. However, initial metabolic differences were not retained over time. Similarly, growth rates were stimulated by exercise, potentially because their lower standard metabolic rate reflected more efficient resource use and the ability to efficiently gain weight; however, the positive growth response also weakened with time. These results indicate that exercise could play an important role in the development of this species; however, the timing (e.g. yellowtail life stage and duration of exercise) and environmental variables (e.g. temperature and flow speed) likely play important roles in optimizing the response. 


\section{CHAPTER 1: INTRODUCTION}

\section{Life history of Yellowtail}

Yellowtail is the common name for a group of carangid fishes in the genus Seriola that are found in subtropical waters around the world (Nakada, 2008). There are several species of Seriola, including the California Yellowtail $S$. dorsalis which is common to waters off the coast of California and Baja California, Mexico, but can range from southern Washington state to Mazatlán, Mexico (Baxter, 1960). Local Southern California stocks are mostly composed of yellowtail from central and northern Baja that move north in early spring before heading back south in late summer and fall (Baxter, 1960), although some reside off the California coast year-round. The species in this region was previously known as a subspecies of Seriola lalandi, but recent genetic work has shown significant distinction within the Seriola lalandi complex, and this population in the northeast Pacific was re-designated as Seriola dorsalis (Gill) (MartinezTakeshita et al., 2015).

California Yellowtail are highly mobile fish, traveling greater distances earlier in life than at older ages (Baxter, 1960). They are opportunistic feeders and have a varied diet, eating small fish such as anchovy, mackerel, and sardine, along with pelagic red crab and squid (Baxter, 1960). As some of the larger fish in the Carangidae family, they can grow to $130-150 \mathrm{~cm}$ fork length and approximately $40 \mathrm{~kg}$ (Baxter, 1960; Sala et al., 2003). These fish typically reach sexual maturity between 2-3 years old and are generally thought to live about 13-15 years 
(Collins, 1973). They have a fusiform body shape with a narrow caudal peduncle and deeply forked tail. Their streamlined shape reduces drag and makes them agile, fast swimmers. Yellowtail are commercially and recreationally important in California and Mexico, but California currently has no stock assessment or fishery management plan in place for this species (James, 2014), though basic catch limits exist in both California and Mexico.

\section{Aquaculture overview}

Aquaculture is a broad term used to refer to the raising and harvesting of aquatic organisms. Current commercial aquaculture includes finfishes, mollusks, crustaceans, and aquatic plants and algae, however finfish culture is most relevant to this thesis. As of 2014 there were 362 species of finfish being cultured, providing millions of jobs in nearly 200 countries around the world (FAO, 2016). Marine capture fishery production has been mostly stagnant since the 1980s, due to many stocks being fully fished, and this plateau in wild fisheries production has led to an increased reliance on aquaculture in recent years to supply the evergrowing demand for fish to feed the growing global population (FAO, 2016). Aquaculture is largely used to produce fish for direct consumption, and since 2012, aquaculture of finfish has grown from 44.2 million tonnes to 49.8 million tonnes, and represented nearly 50\% of all aquaculture products in 2014 (FAO, 2016). Additionally in 2014, production of farmed fish was greater than wild capture in 35 countries (FAO, 2016), underscoring its global importance. Aquaculture products are also used in fishmeal, fish oil, bait, pharmaceuticals, 
and livestock feed, with the US being the largest importer of fish and fisheries products (FAO, 2014, 2016).

Aquaculture of finfishes can take place in inland tanks or ponds, or in various types of ocean pens. Land-based tanks can either be recirculating aquaculture systems (RAS) or flow-through systems. In a contained inland aquaculture system, there are many factors to consider in order to maintain a healthy environment and healthy animals. These factors include: oxygen saturation, flow speed, photoperiod, ammonia concentration, food availability, food type, $\mathrm{pH}$, temperature, and stocking density (Colt, 2006). The optimal parameters for growth are not only different between species but can also vary with life stage for a given species.

\section{Aquaculture of Seriola}

There are certain criteria for selecting suitable fish for aquaculture, including: marketability, food requirements, reproductive strategy, landing price, optimum growth temperature, and maximum size (Le François et al., 2002). Seriola species have been identified as a group with ideal characteristics for warm water aquaculture. Seriola have fast growth rates, reach a large maximum body

size, demonstrate adaptability to hatchery production and pen culture, and provide high value sashimi products as well as premium fish fillets. Several Seriola species are successfully cultured in many countries and have been spawned, hatched and reared successfully in captivity (Moran et al., 2007; Stuart and Drawbridge, 2013; Yang et al., 2016). However, in some countries, the 
aquaculture cycle begins with capturing wild seed (young juveniles), which is less sustainable than producing captive seed, and can be a bottleneck in production, especially with declining availability of wild seed (Nakada, 2002, 2008). Recent research in larval rearing techniques had opened up opportunity for expanding Seriola aquaculture development (Stuart and Drawbridge, 2013); however, further research is needed to optimize the entire rearing process.

Currently, Seriola spp. are cultured in the US, Chile, South-Africa, Japan and Australia. In Japan, yellowtail (mainly S. quinqueradiata) are cultured in net pens off the coast. These pens are typically $30 \mathrm{~m}$ x $30 \mathrm{~m}$ x $15 \mathrm{~m}$ and hold 25,000 fish. The fish are fed formulated extruded pellets primarily made from sardines. There are complications with net pen culture largely due to inconsistency of conditions such as temperature. Higher-than-optimal temperature can lead to increased parasite activity (Nakada, 2002), and lower-than-optimal temperatures can lead to sub-optimal growth (Brown et al., 2011) and altered swimming characteristics (Palstra and Planas, 2011). Stocking density is also a concern in culture systems. Large, active fish like Seriola need sufficient space to exercise in order to build muscle, and often the stocking density in culture pens is too high to allow this behavior (Nakada, 2002). In crowded systems, fish are forced to swim slower than their optimal swimming speed which can lead to the reallocation of energy (that would have been used for swimming) towards more aggressive, and potentially harmful, behaviors (Palstra and Planas, 2011).

Seriola are highly active fish and thus require significant resources (e.g. food and oxygen) to maintain their higher metabolic rates compared to other 
common aquaculture fishes such as salmonids. This equates to potentially greater investment in resources and infrastructure to properly rear Seriola; however, rearing practices (environmental parameters, equipment etc.) for optimal health and production aren't fully understood yet. The increased dependence on aquaculture for food, potential need to adapt rearing protocols for active species, and the increasing interest in culturing Seriola, indicate a need for ongoing research to better understand Seriola growth and development in aquaculture.

\section{A common problem: uninflated swim bladders}

In addition to the challenges mentioned above, a very common issue with several aquaculture species is a failure to inflate the swim bladder during larval development. Since swim bladders are used by most fish species to regulate buoyancy, a fish with an uninflated bladder would likely need to expend more energy to maintain hydrostatic equilibrium, which could impact energy allocation toward growth (Bone et al., 1995; Brix, 2002; Steen, 1970). Inflation failure has been seen in as much as $80 \%$ of larvae from a given spawn of S. dorsalis (Kevin Stuart, personal communication), which is similar to that observed in some other species (see Woolley and Qin, 2010 for review), and with such high rates, this deformity could pose a significant problem for commercial production, as these fish are often assumed to be inferior. The prevalence of this deformity underscores the importance of further research on long-term growth and development of cultured species, which will be especially important for $S$. dorsalis as the culture of this species grows in popularity. 


\section{Fish musculature}

Knowledge of growth and development of fish reared in a culture setting is important for understanding growout duration and determining production capabilities. From a production standpoint, the most important growth is that of the musculature. The myotome of most fish contains two types of muscle, red myoglobin-rich slow-twitch muscle, and white fast-twitch muscle. In Seriola, red muscle is located just under the skin and atop the white muscle mass (which forms the bulk of the musculature) in a thin layer running along the mid-lateral aspect of the fish. Several characteristics distinguish each type of muscle, including: color, enzyme activity, function, mitochondrial content, and blood supply (Bone et al., 1978).

It is generally accepted that at low swimming speeds, red fibers are engaged, while white fibers are active at high speeds and only for short bursts. This is supported by histochemical analysis that has shown higher levels of oxidative enzymes in red muscle (Ogata and Mori, 1964) which uses aerobic metabolism to power routine activity, whereas white muscle respires anaerobically, through use of glycogen, to power fast twitch responses at high speeds. At intermediate speeds, the involvement of different muscle types is highly variable and species-dependent (Bone et al., 1978). Johnston and Moon (1979) found that Coalfish (Pollachius virens) engaged white muscle fibers at speeds as low as $0.8-2.0$ lengths $\mathrm{s}^{-1}$ which was considered a sustainable speed for the fish tested. Additionally, Johnston and Moon (1980) used electromyography to show that red and white muscles are used in sustained swimming in Brook 
Trout (Salvelinus fontinalis) and similar results were found at intermediate swimming speeds for Rainbow Trout (Salmo gairdneri) (Hudson, 1973). This suggests that there is some overlap in the function of red and white muscles and that both anaerobic and aerobic pathways may be used to power sustained swimming.

Muscle growth in fish is a function of hyperplasia (increase in cell number, muscle fiber recruitment) and hypertrophy (increase in cell diameter and subsequent muscle fiber diameter). Both of these processes can be influenced by environmental factors such as diet/nutrition, exercise, light cycle, and temperature (Johnston, 1999). White muscle growth is especially important in aquaculture, as it is the final product for species such as S. dorsalis that are produced most often for direct human consumption. This thesis attempts to assess growth of S. dorsalis and further enhance it through sustained exercise.

\section{Recent Seriola research}

Recent work done by Wegner et al. (in review) used several established swimming and metabolic measurements to compare fitness of aquaculture-reared and wild-caught $S$. dorsalis in order to evaluate the effects of captive rearing and determine areas for improvement. This work found that juvenile hatchery-reared yellowtail are less physically fit than juvenile wild-caught yellowtail, having a significantly higher standard metabolic rate $\left(7.36 \pm 2.28\right.$ vs. $3.97 \pm 1.62 \mathrm{mgO}_{2}$ $\left.\mathrm{kg}^{-1} \min ^{-1}\right)$, significantly slower mean maximum sustainable swimming speed $\left(4.16 \pm 0.62\right.$ vs $\left.4.80 \pm 0.52 \mathrm{BL} \mathrm{s}^{-1}\right)$, and reduced aerobic scope ( $9.16 \pm 3.40$ vs. 
$15.77 \pm 5.78 \mathrm{mgO}_{2} \mathrm{~kg}^{-1} \mathrm{~min}^{-1}$; Wegner, in review). Reduced fitness of hatchery fish as compared to wild-caught conspecifics has been seen in several other culture species such as Gilthead Sea Bream (Sparus aurata (Basaran et al., 2007)), Rainbow Trout (Salmo gairdneri (Duthie, 1987)), Atlantic Salmon (Salmo salar (Hammenstig et al., 2014; McDonald et al., 1998; Shustov and Shchurov, 1988)), and Brown Trout (Salmo trutta (Pedersen et al., 2008)). This inferiority in fitness could translate to less efficient resource use, leading to greater costs to rear fish to market size.

Sustained exercise has been shown to be a promising non-genetic, nonhormonal means of improving several aspects of fitness (e.g., growth, feed conversion, and potentially swimming performance) and some work in this area has examined Seriola species. Brown et al. (2011) found that S. lalandi, had 3\% greater mass and improved swimming efficiency as measured immediately following 28 days of sustained exercise. Fingerling S. quinqueradiata were up to $34 \%$ larger and had improved feed efficiency as a result of 28 days of sustained exercise (Yogata and Oku, 2000). Most recently, Palstra et al. (2015) found a 11\% improvement in mass and more efficient feed conversion in S. lalandi exercised for a mere 18 days at optimal swimming speeds. Though exercise has been shown to produce positive benefits in several Seriola species, the magnitude of the response varies due to differences in methodology (e.g. swimming velocity and duration, temperature, and feeding regime). Peters (2009) conducted some of the only work to specifically examine effects of exercise on $S$. doralis and found that fish that experiences sustained exercised for 34 days at $60 \%$ of their critical 
swimming speed, were approximately $15 \%$ larger than the unexercised control group and had a significantly higher maximum sustainable swimming speeds. These results show promising benefits of exercise for S. dorsalis; however, many factors relating to exercise, for example duration needed to elicit a positive response and how long any benefits last, are still unknown. Understanding the response to exercise will help to determine optimal exercise parameters for the greatest benefit and subsequent best-practices for growout of this species.

\section{Metrics and goals of this thesis}

In the two studies that comprise this thesis, several metrics of swimming and metabolic performance were measured and compared across groups in order to better understand (1) the effect of swim bladder uninflation on growth and development and how fitness of hatchery-reared fish compares to that of wild conspecifics, and (2) the effect of exercise duration on growth, feed conversion ratio, and metabolic performance of healthy hatchery-reared fish. These metrics included: critical swimming speed, optimal swimming speed, cost of transport, aerobic scope, metabolic rate, growth rate, and feed conversion ratio. These measures are important for creating optimal rearing parameters based on a sound understanding of the physiology and development of S. dorsalis. 


\section{CHAPTER 2: SWIM BLADDER STUDY}

\section{Introduction}

Yellowtails, or amberjacks, are coastal pelagic carangid fishes, belonging to the genus Seriola, found in tropical and subtropical waters around the world. Seriola spp. have been identified as a group with ideal characteristics for aquaculture, demonstrating adaptability to hatchery production and pen culture. Their fast growth to market size, and high value sashimi products as well as premium fish fillets make them attractive candidates for further aquaculture development. In some countries, the aquaculture cycle for Seriola begins with capturing wild seed. However, because of regional availability and a general declining trend in catch numbers (Nakada, 2002, 2008), the use of wild seed is often seen as a bottleneck to commercial production and is thus thought to be less sustainable than producing captive seed. While recent research in larval rearing techniques has led to improvements in captive-bred larval quality and survivorship (Moran et al., 2007; Stuart and Drawbridge, 2013; Yang et al., 2016), further research is needed to understand and optimize hatchery production.

This study examines the California Yellowtail, Seriola dorsalis, which is common to waters of the Northeast Pacific, and can range from southern Washington State to Mazatlán, Mexico (Baxter, 1960). This species was previously thought to be a subspecies of Seriola lalandi, but recent research has shown significant genetic and meristic distinction that justified its separation within the Seriola complex (Martinez-Takeshita et al., 2015). Any effect that these differences may have on growth and development of $S$. dorsalis is not well 
understood and could potentially require adaptation of production practices currently used for other Seriola species. Previous larval research has demonstrated that $S$. dorsalis can been spawned, hatched and reared successfully in captivity (Stuart and Drawbridge, 2013), eliminating the need for wild seed, which are not readily available for this species. Though larval research of $S$. dorsalis has made great strides, additional research is needed, particularly in assessing and minimizing the impact of deformities common to hatcheries.

A significant challenge to the aquaculture of many finfish species is the failure of fish to inflate their swim bladder during larval development. This deformity can affect large portions of post-larval fish and is a significant problem with many cultured species including Gilthead Seabream (Sparus auratus (Prestinicola et al., 2014)), European Seabass (Dicentrarchus labrax (Chatain, 1989)), Walleye (Stizostedion vitreum (Marty et al., 1995)), Striped Trumpeter (Latris lineata (Trotter et al., 2001)), Southern Bluefin Tuna (Thunnus maccoyii (Woolley et al., 2013)), and Yellowtail Kingfish (Seriola lalandi (Woolley et al., 2014)). Current larval rearing methods for $S$. dorsalis can result in up to $80 \%$ of a given spawn with uninflated swim bladders (Kevin Stuart, personal communication), which is similar to what has been seen in other species (see Woolley and Qin, 2010 for review). Since swim bladders are used by most fish species to regulate buoyancy, a fish with an uninflated bladder would likely need to expend more energy to maintain hydrostatic equilibrium, which could impact energy allocation toward growth (Bone et al., 1995; Brix, 2002; Steen, 1970). 
Like many other important aquaculture species, Seriola spp. are physoclists as adults, but transient physostomes as larvae, and must gulp air at the surface to inflate their swim bladders before the pneumatic duct connecting the swim bladder to the esophagus closes. In S. lalandi, swim bladder inflation takes place from 2-5 days post hatch, (Woolley and Qin, 2013), which is consistent with observations for S. dorsalis (Stuart and Drawbridge, 2013), leaving a narrow window of time for inflation. While the etiology of inflation failure is not entirely understood, it is often attributed to a number of variables, including stocking density, lighting, feed type/composition, and tank flow dynamics, that potentially inhibit or discourage fish from gulping air at the surface. These uninflated fish are often assumed to be inferior, and are typically sacrificed at a young age, resulting in large losses of potential product (Woolley and Qin, 2010). As such, the failure of bladder inflation can pose a significant barrier to the commercial production.

Several studies have reported reduced growth in larvae with uninflated swim bladders (Battaglene and Talbot, 1992; Chatain, 1989; Czesny et al., 2005; Hashimoto et al., 2012; Jacquemond, 2004b; Kindschi and Barrows, 1993) however, the magnitude of the response is variable. Some species, such as the European Perch (Perca fluviatilis), that demonstrated reduced growth in the larval stage due to swim bladder uninflation, were able to inflate their swim bladder later in development and differences in growth progressively disappeared (Jacquemond, 2004a). Moreover, swim bladder inflation only stunted the growth of Pacific Bluefin Tuna (Thunnus orientalis) up to $30 \mathrm{dph}$, after which there was no significant difference in size of fish with and without inflated swim bladders 
(Kurata et al., 2015). The effect of swim bladder uninflation on growth and development of fish species is thus complex and varied, and despite the prevalence of this deformity, research on long-term growth and development is still needed for most species to inform hatcheries of the value of rearing these fish.

This study uses a number of recently established swimming and metabolic metrics for $S$. dorsalis (Wegner et al., in review) to examine the effects of swim bladder inflation on yellowtail health, fitness, and development. Specifically, hatchery-reared fish with inflated and uninflated swim-bladders were compared to wild-caught $S$. dorsalis in terms of critical swimming speed, standard metabolic rate, cost of transport, and aerobic scope. In addition, somatic growth and feed conversion were monitored and compared between these three groups over a 32 week growout period.

\section{Methods}

\section{$\underline{\text { Fish Collection and Sorting }}$}

Hatchery-bred California Yellowtail, S. dorsalis, were produced by Hubbs-SeaWorld Research Institute (HSWRI, San Diego, CA) from wildcaptured broodstock and transferred to the experimental aquarium facility at the Southwest Fisheries Science Center (SWFSC, La Jolla, CA) at approximately 75 days post hatch. Prior to transfer, fish were sorted into two groups, one group with fully functional and inflated swim bladders ("inflated"), and a second group with non-functional, uninflated swim bladders (“uninflated"). Sorting was done by 
mildly anaesthetizing the fish using MS-222 (tricane methanesulphonate, $75 \mathrm{mg}$ $\mathrm{L}^{-1}$ ) and placing them in a hypersaline solution (50 ppt). Positively buoyant fish were determined to have properly inflated swim bladders, while negatively buoyant fish were determined to have uninflated swim bladders (Woolley and Qin, 2010). Fish were allowed to recover from transfer stress for approximately one week before experimentation began, at which point they had resumed normal eating and swimming behavior for several days. Wild juvenile California Yellowtail associated with drifting kelp off the coast of San Diego, CA were captured by hook and line and transported to the experimental aquarium at the SWFSC. These fish were held in captivity for up to seven weeks before experimentation began to allow sufficient time for recovery from capture and transition to a commercial pellet feed. All transport, husbandry, and experimentation were done according to the SWFSC Institutional Animal Care and Use Committee protocol \#SW1401.

\section{Yellowtail Growout and Feed Conversion}

A 32-week growout period was used to examine potential differences in somatic growth between experimental groups (wild $n=39$, inflated $n=40$, uninflated $n=40$ ). Each group was housed in separate oval tanks (304 x 154 x 80 $\mathrm{cm}$, volume $=3.34 \mathrm{~m}^{3}$ ) supplied with $\sim 23 \mathrm{~L} \mathrm{~min}^{-1}$ of flow-through filtered seawater drawn from the end of the Scripps Institution of Oceanography pier. Water temperature $\left(18.00-18.13^{\circ} \mathrm{C}\right)$ and dissolved oxygen levels were kept consistent between tanks, and the lack of directional flow (e.g., spray/flow bars were not used) allowed for more spontaneous swimming activity in each tank. 
Somatic measurements [total length or body length (BL), fork length (FL), body mass, and girth] were taken for all fish from each group at the start of the growout period (“Initial”), and again after 32 weeks (“Final”) by lightly anaesthetizing yellowtail with MS-222 (80 $\left.\mathrm{mg} \mathrm{L}^{-1}\right)$. Condition factor $(\mathrm{CF})$ for each fish was calculated using:

$$
\mathrm{CF}=\left(\mathrm{M} / \mathrm{BL}^{3}\right) \times 100
$$

During growout all fish were fed commercial pellets for yellowtail (EWOS, Surrey, BC, Canada) two to four times daily, six days a week. For the first eight weeks, each group was fed $5 \%$ body mass day ${ }^{-1}$ in pellets; however, as the fish easily consumed this amount, the feeding regime was amended for the remaining 24 weeks to hand feed to satiation as to not limit growth. Feed conversion ratio (FCR) was calculated for this 24 -week period using:

$$
\text { FCR }=\frac{\text { total dry feed consumed }(\mathrm{g})}{\text { total weight gained }(\mathrm{g})}
$$

$\underline{\text { Swim Tunnel Trials }}$

In order to examine potential differences in swimming and metabolic fitness between groups, several yellowtail fitness metrics were measured through incremental velocity tests using variable-speed Brett-style swim tunnel respirometers (Loligo Systems, Viborg, Denmark). This was done at two points during the growout period using randomly selected fish from each group that were fasted for 20 to 24 hours. Fish were tested at $64.3 \pm 18.1 \mathrm{~g}$ and $18.2 \pm 1.6 \mathrm{~cm} \mathrm{BL}$ (Size A, mean \pm standard deviation: wild $n=8$, inflated $n=6$, uninflated $n=7$ ) using 
a 5.4 L respirometer with a $30 \times 7.5 \times 7.5 \mathrm{~cm}$ working section, and again approximately four months later when fish were $415.26 \pm 57.97 \mathrm{~g}$ and $32.31 \pm$ $1.50 \mathrm{~cm}$ BL (Size B: wild $n=8$, inflated $n=7$, uninflated $n=8$ ) using a 29.6 L respirometer with a $55 \times 14 \times 14 \mathrm{~cm}$ working section. Testing was restricted to sizes where fish could comfortably fit in the working section and successfully complete the swimming regime. The median time in captivity for the wild fish at Size A was 71 days, and at Size B was 185 days.

The swim tunnel respirometer was submerged in a buffer tank supplied with filtered seawater at approximately $18^{\circ} \mathrm{C}$, consistent with the growout temperature, and water flow into and out of the tunnel was controlled by manual valves. Fish were acclimated in the swim tunnel at a low flow speed (typically under $40 \mathrm{~cm} \mathrm{~s}^{-1}$ ) for at least one hour before incremental velocity testing began. The acclimation period started once the fish was swimming steadily with a regular gait. Following the acclimation period, fish were forced to swim against a calibrated flow speed for 30 minutes, after which the flow speed was raised by 5 $10 \mathrm{~cm} \mathrm{~s}^{-1}$. This procedure was repeated until the fish fatigued, which was indicated by resting against the back fence of the working section and the inability to swim forward when encouraged through visual cues.

Following each trial, swimming speed was adjusted for the solid blocking effect of both the cylindrical vane wheel flow meter probe (Höntzsch Gmbh, Waiblingen, Germany) used to calibrate the swim tunnel, and for the size-specific blocking effect of each fish. To account for the flow meter blocking effect, the following equation was used: 


$$
A_{1} V_{1}=A_{2} V_{2}
$$

where $A_{1}$ is the cross-sectional area of the flume $\left(\mathrm{cm}^{2}\right)$ minus the cross-sectional area of the flow meter $\left(\mathrm{cm}^{2}\right), V_{1}$ is the velocity as measured by the flow meter $(\mathrm{cm}$ $\left.\mathrm{s}^{-1}\right), \mathrm{A}_{2}$ is the cross-sectional area of the flume without the flow meter present $\left(\mathrm{cm}^{2}\right)$, and $V_{2}$ is the true velocity without the flow meter blocking effect $\left(\mathrm{cm} \mathrm{s}^{-1}\right)$. The solid blocking effect of each fish was accounted for using the Bell and Terhune equation (1970):

$$
\epsilon_{\mathrm{s}=} \tau \lambda\left(\frac{A_{\mathrm{O}}}{A_{\mathrm{T}}}\right)^{\frac{3}{2}}
$$

where $\epsilon_{\mathrm{s}}$ is the fractional error caused by the blocking effect, $\tau$ is the factor for the flume cross-sectional shape $(0.8)$, and $\lambda$ is the shape coefficient for the object [in this case a streamlined object coefficient of 0.5 multiplied by the $(\mathrm{BL}(\mathrm{cm}) \div$ fish thickness (cm))]. Fish thickness (diameter) was calculated as $G / \pi$ where $G$ is girth. $A_{\mathrm{O}}$ is the maximum cross-sectional area of the fish $\left(\pi r^{2}\right)$, and $A_{\mathrm{T}}$ is the crosssectional area of the flume $\left(\mathrm{cm}^{2}\right)$. This error coefficient was then used to find the true flow speeds experienced by the fish $\left(V_{\mathrm{F}}\right)$ using:

$$
V_{F}=V_{T}\left(1+\epsilon_{S}\right)
$$

where $V_{\mathrm{T}}$ is the flow speed in the empty flume $\left(\mathrm{cm} \mathrm{s}^{-1}\right)$, and $\epsilon_{\mathrm{S}}$ is the fractional error as calculated above. Following all flow speed adjustments, critical swimming speed $\left(U_{\text {crit }}, \mathrm{cm} \mathrm{s}^{-1}\right)$ was determined for each fish based on Brett's (1964) equation: 


$$
U_{\text {crit }}=U_{\mathrm{i}}+\left(\frac{t_{\mathrm{f}}}{t_{\mathrm{i}}} \times U_{\mathrm{ii}}\right)
$$

where $U_{\mathrm{i}}$ is the highest speed sustained for a full 30 -minute increment $\left(\mathrm{cm} \mathrm{s}^{-1}\right), t_{\mathrm{f}}$ is the time swam at the fatigue velocity in minutes, $t_{\mathrm{i}}$ is the prescribed time interval for each velocity increment (30 minutes), and $U_{\text {ii }}$ is the last incremental velocity step increase $\left(\mathrm{cm} \mathrm{s}^{-1}\right)$.

\section{$\underline{\text { Respirometry and Metabolic Performance }}$}

Oxygen consumption data were recorded for each fish in the respirometer while swimming at each 30-minute velocity step using a Fibox 3 fiber optic oxygen transmitter (PreSens Precision Sensing GmbH, Regensburg, Germany). Approximately two minutes after each step-wise increase in speed, the respirometer was sealed and the oxygen level (as \% air saturation) was recorded every five seconds using PreSense software version PST3v602. Oxygen saturation within the respirometer was not allowed to drop below $80 \%$ before the system was manually flushed and brought back to full saturation, at which point oxygen measurements were repeated if time allowed. The recorded decrease in oxygen saturation was used to calculate the metabolic rate $\left(\mathrm{M}_{2}\right)$ at each swimming speed. If multiple oxygen traces were completed during a given speed, they were averaged to find the mean oxygen consumption at that speed.

At the conclusion of each swim tunnel trial, the fish was removed from the working section, and the chamber was resealed for a measurement of background respiration, which was then subtracted from the fish's calculated $M_{O_{2}}$. Each fish 
was then lightly anaesthetized using MS-222 $\left(80 \mathrm{mg} \mathrm{l}^{-1}\right)$ to measure size (BL, FL, mass, and girth), and then temporarily placed in a holding tank, separate from the growout tanks, to ensure it was not repeatedly tested in the swim tunnel at a given size point (Size A or Size B). Once all respirometry measurements were completed at a given size for all three groups, fish were placed back in their original tanks for continued growout.

The mean water temperature for all swim tunnel trials was $18.17 \pm 0.30$ ${ }^{\circ} \mathrm{C}$; however, temperature ranged from $16.94-19.38^{\circ} \mathrm{C}$, so for direct comparison between groups metabolic data were adjusted for temperature using the equation:

$$
\left(M_{\mathrm{O}_{2}}\right)_{2}=\left(M_{\mathrm{O}_{2}}\right)_{1} Q_{10}^{\left(\frac{T_{2}-T_{1}}{10}\right)}
$$

where $T_{2}$ is the desired temperature $\left(18.0{ }^{\circ} \mathrm{C}\right), T_{1}$ is the measured temperature $\left({ }^{\circ} \mathrm{C}\right),\left(M_{\mathrm{O}_{2}}\right)_{2}$ is the oxygen consumption $\left(\mathrm{mgO}_{2} \mathrm{~min}^{-1}\right)$ at $T_{2},\left(M_{\mathrm{O}_{2}}\right)_{1}$ is the oxygen consumption at $T_{1}$, and $Q_{10}=2$ (Pirozzi and Booth, 2009). In addition, metabolic data for each fish were scaled to a common body mass (65 $\mathrm{g}$ at Size A and $410 \mathrm{~g}$ at Size B) using mass ${ }^{0.80}$ (Brett and Groves, 1979) for more direct comparison between groups.

For each fish, $M_{\mathrm{O}_{2}}$ was plotted against swimming speed, which typically resulted in a checkmark-shaped curve (common for pelagic fishes), with increased oxygen consumption at low swimming speeds representing the added energetic cost needed to maintain hydrostatic equilibrium at these inefficient velocities (Webb, 1998). $M_{\mathrm{O}_{2}}$ values at low speeds that were higher than the vertex of the curve were therefore excluded (Sepulveda et al., 2003) before the aggregate data 
were used to generate regressions for $M_{\mathrm{O}_{2}}$ in relation to swimming speed for each group (inflated, uninflated, wild) at each size measured (Size A, B). Regression relationships between oxygen consumption and swimming speed were determined using a bootstrap analysis in which 10,000 exponential regression replicates were created from aggregate data for each group at each size using RStudio (v1.0.143). Bootstrap regressions were then extrapolated to a swimming speed of $0 \mathrm{~cm} \mathrm{~s}^{-1}$ and averaged to estimate standard metabolic rates (SMR) for each group and size. Aerobic scope for each group and size was determined using individual fish data to estimate SMR and then subtracting it from the highest metabolic rate recorded for that fish.

To understand metabolic costs associated with level of swimming activity, $M_{\mathrm{O}_{2}}$ data from individual fish were used to calculate the cost of transport (COT, $\mathrm{mgO}_{2} \mathrm{~kg}^{-1} \mathrm{~m}^{-1}$ ) at each swimming speed using the equation:

$$
\mathrm{COT}=M_{\mathrm{O}_{2}} / U
$$

where $U$ is the swimming speed $\left(\mathrm{m} \mathrm{min}^{-1}\right)$. COT was graphed against swimming speed with the lowest point (vertex) of the polynomial regression curve representing the optimal swimming speed $\left(U_{\mathrm{opt}}\right)$ at which the cost of transport is lowest. The vertex, or $U_{\mathrm{opt}}$, was found by taking the derivative of the polynomial regression for each fish, setting it equal to zero, and solving for ' $\mathrm{x}$ '. The $U_{\mathrm{opt}}$ was then used to find the lowest value of COT by plugging the calculated ' $\mathrm{x}$ ' back into the original polynomial equation. The result, or min COT, for each individual fish was then used to compare across groups. 


\section{$\underline{\text { Statistical Analysis }}$}

Metrics of growth, swimming performance, and aerobic scope were determined as means \pm standard deviation from individual fish data and potential differences between inflated, uninflated, and wild yellowtail were compared statistically using a single factor ANOVA, followed by a Tukey post-hoc test if $P \leq 0.05$. Bootstrapped regression equations of $M_{\mathrm{O}_{2}}$ in relation to swimming speed were used to test for significant differences in the metabolism of different groups at different swimming speeds. Significant differences in the metabolism between groups was confirmed if less than $5 \%$ of the replicate regressions intersected within the range of swimming speeds being compared.

\section{Results}

\section{Growth and Feed Conversion}

At the start of the study, fish body mass $(44.3 \pm 12.4 \mathrm{~g})$, FL $(14.9 \pm 1.4$ $\mathrm{cm})$, and girth $(8.5 \pm 0.9 \mathrm{~cm})$ did not differ significantly between groups; however, the wild fish had significantly longer BL than the inflated fish (16.6 \pm $2.4 \mathrm{~cm}$ vs. $15.7 \pm 0.7 \mathrm{~cm}$ respectively), and a significantly lower condition factor than both other groups $(0.94 \pm 0.08$ vs. $1.10 \pm 0.07$ inflated, $1.09 \pm 0.08$ uninflated). After a 32-week growout, inflated fish had significantly greater mass $(758.6 \pm 92.7$ g vs. $671.1 \pm 128.9 \mathrm{~g}$ wild, $636.1 \pm 80.4 \mathrm{~g}$ uninflated $)$ and girth $(23.2 \pm 1.1 \mathrm{~cm}$ vs. $21.6 \pm 1.7 \mathrm{~cm}$ wild, $21.5 \pm 1.2 \mathrm{~cm}$ uninflated $)$ than the other two groups, while uninflated fish had significantly shorter BL $(36.5 \pm 1.9 \mathrm{~cm}$ vs. $38.4 \pm 2.7 \mathrm{~cm}$ wild, $39.6 \pm 2.0 \mathrm{~cm}$ inflated), and significantly higher condition 
factor (1.76 \pm 0.15 vs. $1.18 \pm 0.12$ wild, $1.22 \pm 0.09$ inflated; Figure 1.1). Wild fish had the most efficient FCR (1.41 vs. 1.49 inflated, 2.08 uninflated) and needed $5.8 \%$ less feed than the inflated group, and $47.8 \%$ less feed than the uninflated group to gain equivalent mass.

\section{$\underline{\text { Swimming and Metabolic Performance }}$}

Swimming and metabolic performance data are shown in Tables 1.1 and 1.2 respectively. Critical swimming speed was not significantly different between any of the groups at either Size A or Size B (Table 1.1). The wild fish had a significantly lower SMR than both other groups at Size A $(3.08 \pm 0.23$ vs. $5.60 \pm$ 0.54 inflated, $6.45 \pm 0.66 \mathrm{mgO}_{2} \mathrm{~kg}^{-1} \mathrm{~min}^{-1}$ uninflated), but there was not a significant difference in SMR between groups at Size B (Table 1.2). Figure 1.2 shows aggregate metabolic curves for each group over a range of swimming speeds. At Size A (Figure 1.2 A), wild fish had significantly lower metabolic rates that the uninflated fish for swimming speeds up to $5.7 \mathrm{BL} \mathrm{s}^{-1}$ and the inflated fish up to 5.0 $\mathrm{BL} \mathrm{s}^{-1}$. Inflated fish had significantly lower metabolic rates than the uninflated fish for swimming speeds from 2.5-5.3 $\mathrm{BL} \mathrm{s}^{-1}$. Although the initial significant difference in SMR between groups was not maintained for the approximate four months of growout between Size A and B, the uninflated fish had significantly higher metabolic rates than the inflated fish from 2.3-4.5 BL s${ }^{-1}$, and the wild fish from 1.3 to 4.3 $\mathrm{BL} \mathrm{s}^{-1}$ at Size B (Figure 1.2 B). There was no significant difference in the aerobic scope between groups at either Size A or Size B (Table 1.2). 
Aggregate COT data is shown for Size A and Size B in Figure 1.3 and is intended for visual comparison only, as any significance was determined from individual fish data. Although $U_{\text {opt }}$ was not significantly different between groups at Size A, the wild fish had a significantly lower min COT than either other group at this size $\left(0.24 \pm 0.04\right.$ vs. $0.31 \pm 0.03$ inflated, $0.35 \pm 0.04 \mathrm{mgO}_{2} \mathrm{~kg}^{-1} \mathrm{~m}^{-1}$ uninflated). At Size B, wild fish had a significantly lower $U_{\text {opt }}$ than the uninflated fish $\left(2.64 \pm 0.43\right.$ vs. $\left.3.23 \pm 0.27 \mathrm{BL} \mathrm{s}^{-1}\right)$; however, there was no significant difference in min COT between any groups at Size B (Table 1.1). 
Table 1.1. Metrics of swimming performance for cultured S. dorsalis with properly inflated and uninflated swim bladders compared to wild-caught yellowtail. Values are group means \pm standard deviation. ${ }^{*}$ Indicates significant difference of one group from the other two. ${ }^{* *}$ Used to indicate significant difference between two groups. 


\begin{tabular}{|c|c|c|c|c|c|c|}
\hline Group & $\begin{array}{c}U_{\text {crit }} \\
\text { Size A } \\
\left(\text { BL s s-1) }^{-1}\right)\end{array}$ & $\begin{array}{c}U_{\text {crit }} \\
\text { Size B } \\
\left(\text { BL s s }^{-1}\right)\end{array}$ & $\begin{array}{c}U_{\text {opt }} \\
\text { Size A } \\
\left(\text { BL s s }^{-1}\right)\end{array}$ & $\begin{array}{c}U_{\text {opt }} \\
\text { Size B } \\
\left(\text { BL s s-1 }^{-1}\right)\end{array}$ & $\begin{array}{c}\text { Min COT } \\
\text { Size A } \\
\left(\mathbf{m g O}_{2} \mathbf{k g}^{-1} \mathbf{m}^{-1}\right)\end{array}$ & $\begin{array}{c}\operatorname{Min} \text { COT } \\
\operatorname{Size~B~}_{\left(\mathbf{m g O}_{2} \mathbf{k g}^{-1} \mathbf{m}^{-1}\right)}\end{array}$ \\
\hline Wild & $5.24 \pm 0.62$ & $4.31 \pm 0.35$ & $3.52 \pm 0.20$ & $2.64 \pm 0.43^{* *}$ & $0.24 \pm 0.04 *$ & $0.16 \pm 0.03$ \\
\hline Inflated & $5.38 \pm 0.80$ & $4.42 \pm 0.32$ & $3.49 \pm 0.74$ & $2.99 \pm 0.43$ & $0.31 \pm 0.03$ & $0.16 \pm 0.03$ \\
\hline Uninflated & $5.20 \pm 0.53$ & $4.35 \pm 0.58$ & $3.99 \pm 0.46$ & $3.23 \pm 0.27 * *$ & $0.35 \pm 0.04$ & $0.19 \pm 0.04$ \\
\hline
\end{tabular}


Table 1.2. Metrics of metabolic performance for aquaculture-reared S. dorsalis with properly inflated and uninflated swim bladders compared to wild-caught yellowtail. Mean standard metabolic rates (SMR) were adjusted to a temperature of $18^{\circ} \mathrm{C}$ using a $\mathrm{Q}_{10}=2$, and standardized to $65 \mathrm{~g}$ at Size A, and to $410 \mathrm{~g}$ at Size B using mass ${ }^{0.80}$. Values are group means \pm standard deviation. *Indicates significant difference of one group from the other two. 


\begin{tabular}{lcccc}
\hline Group & $\begin{array}{c}\text { SMR } \\
\text { Size A } \\
\left(\mathbf{m g O}_{2} \mathbf{~ k g}^{-1} \mathbf{m i n}^{-1}\right)\end{array}$ & $\begin{array}{c}\text { SMR } \\
\mathbf{S i z e ~ B} \\
\left(\mathbf{m g O}_{2} \mathbf{~ k g}^{-1} \mathbf{m i n}^{-1}\right)\end{array}$ & $\begin{array}{c}\text { Aerobic Scope } \\
\mathbf{S i z e ~ A} \\
\left(\mathbf{m g O}_{2} \mathbf{~ k g}^{-1} \mathbf{~ m i n}^{-1}\right)\end{array}$ & $\begin{array}{c}\text { Aerobic Scope } \\
\mathbf{S i z e ~ B ~} \\
\left(\mathbf{m g O}_{2} \mathbf{~ k g}^{-1} \mathbf{~ m i n}^{-1}\right)\end{array}$ \\
\hline Wild & $3.08 \pm 0.23^{*}$ & $2.95 \pm 0.22$ & $21.06 \pm 4.26$ & $13.49 \pm 3.03$ \\
Inflated & $5.60 \pm 0.54$ & $3.08 \pm 0.38$ & $18.46 \pm 3.43$ & $16.33 \pm 2.57$ \\
Uninflated & $6.45 \pm 0.66$ & $3.67 \pm 0.50$ & $18.61 \pm 4.71$ & $17.23 \pm 4.13$ \\
\hline
\end{tabular}


Figure 1.1. Comparison of (A) body mass, (B) body length, (C) girth and (D) condition factor of all groups at the start (initial) and end (final) of a 32-week growout period. Statistical significance is only shown between groups within each time point. *Indicates significant difference of one group from the other two. **Used to indicate significant difference between two groups. 


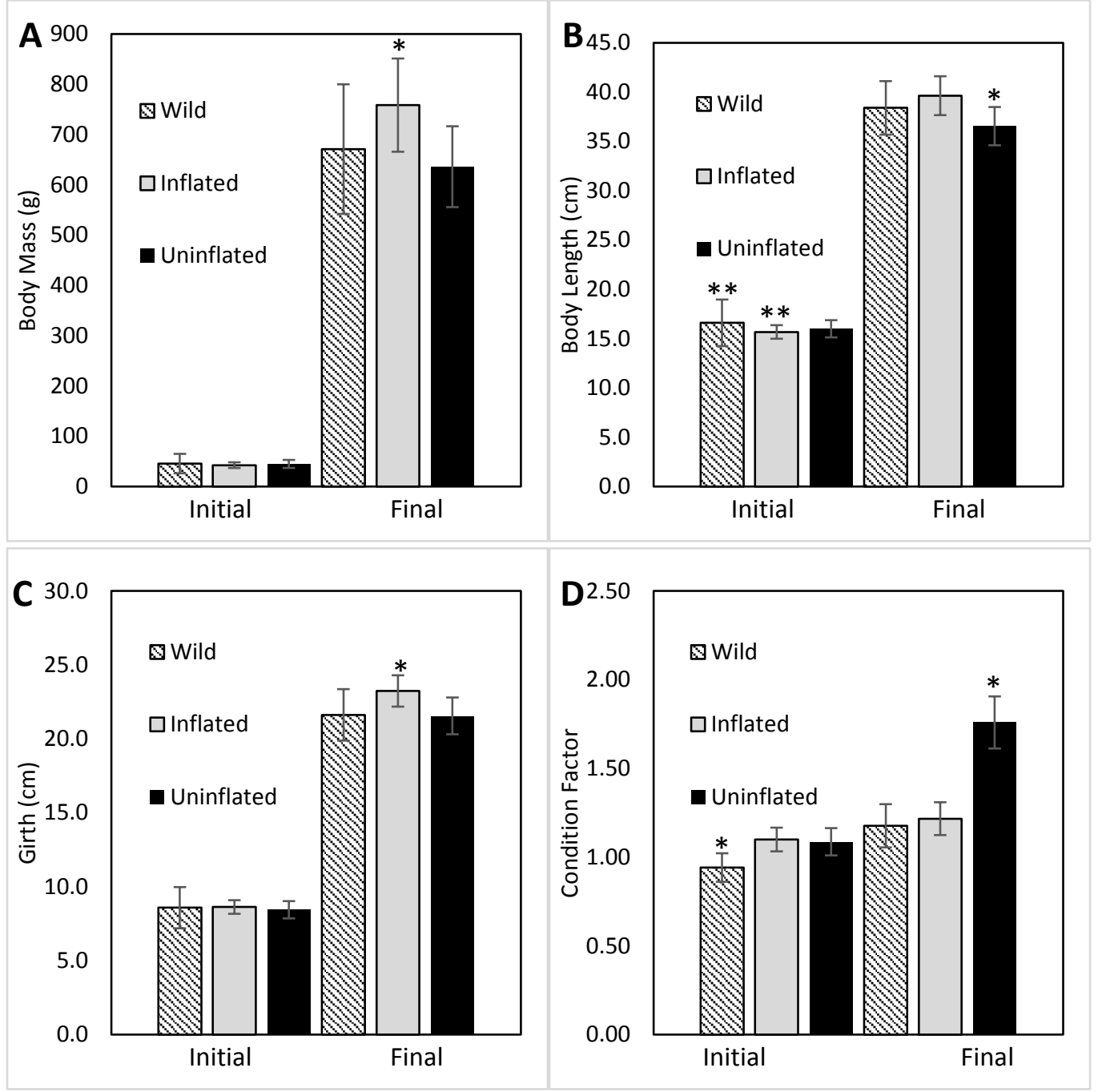


Figure 1.2. Metabolic rate $\left(\mathrm{MO}_{2}\right)$ at various swimming speeds for wild fish (dotted line), inflated fish (grey line), and uninflated fish (black line) at (A) Size A (65 g) and approximately four months later at (B) Size B (410 g). For A, wild $n=8$, inflated $n=6$, uninflated $n=7$. For $B$, wild $n=8$, inflated $n=7$, uninflated $n=8$. 

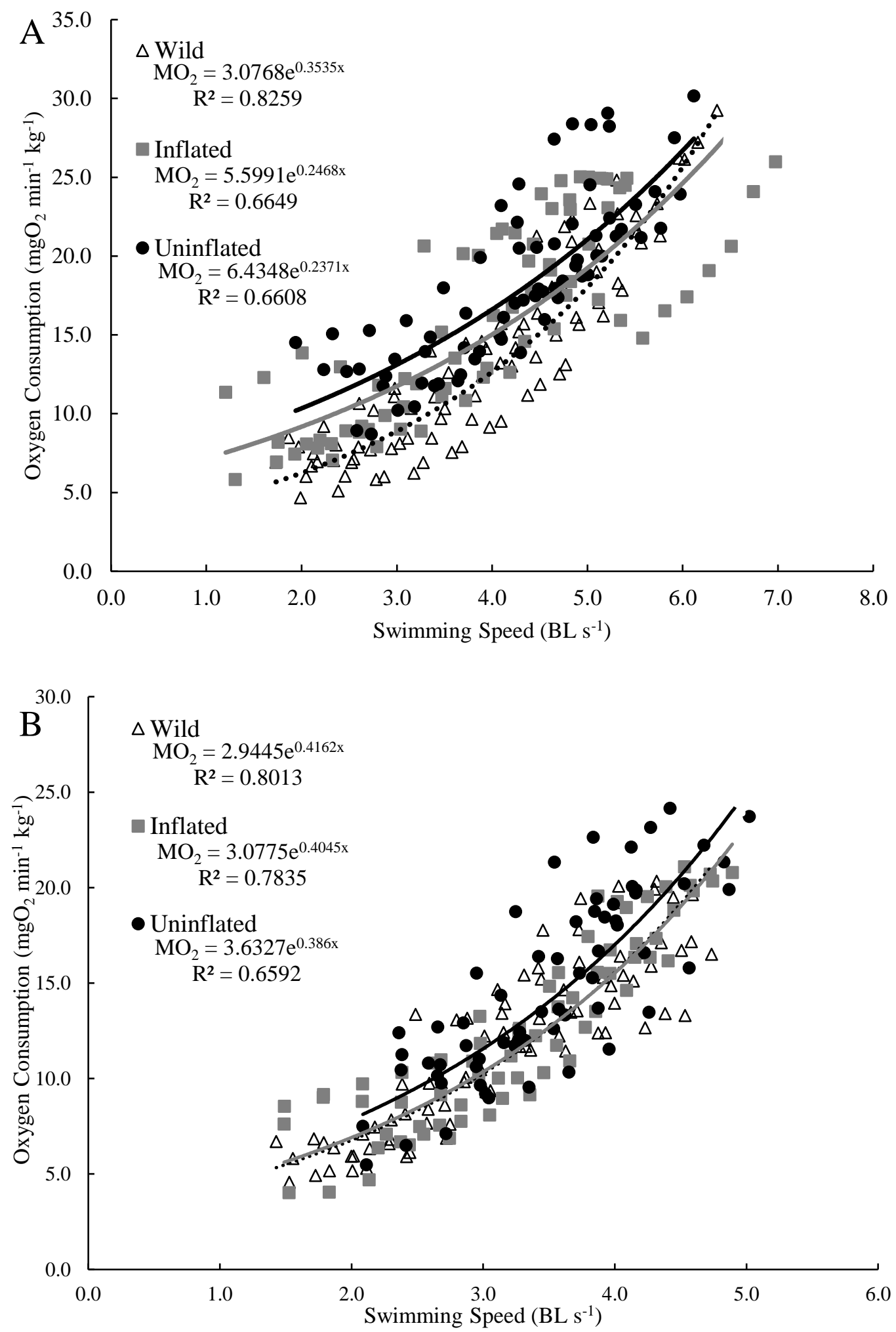
Figure 1.3. Cost of transport (COT) at (A) Size A (65 g) and approximately four months later at (B) Size B (410 g) for wild fish (dotted line), inflated fish (grey line), and uninflated fish (black line). For $A$, wild $n=8$, inflated $n=6$, uninflated $n=7$. For $B$, wild $n=8$, inflated $n=7$, uninflated $n=8$. 

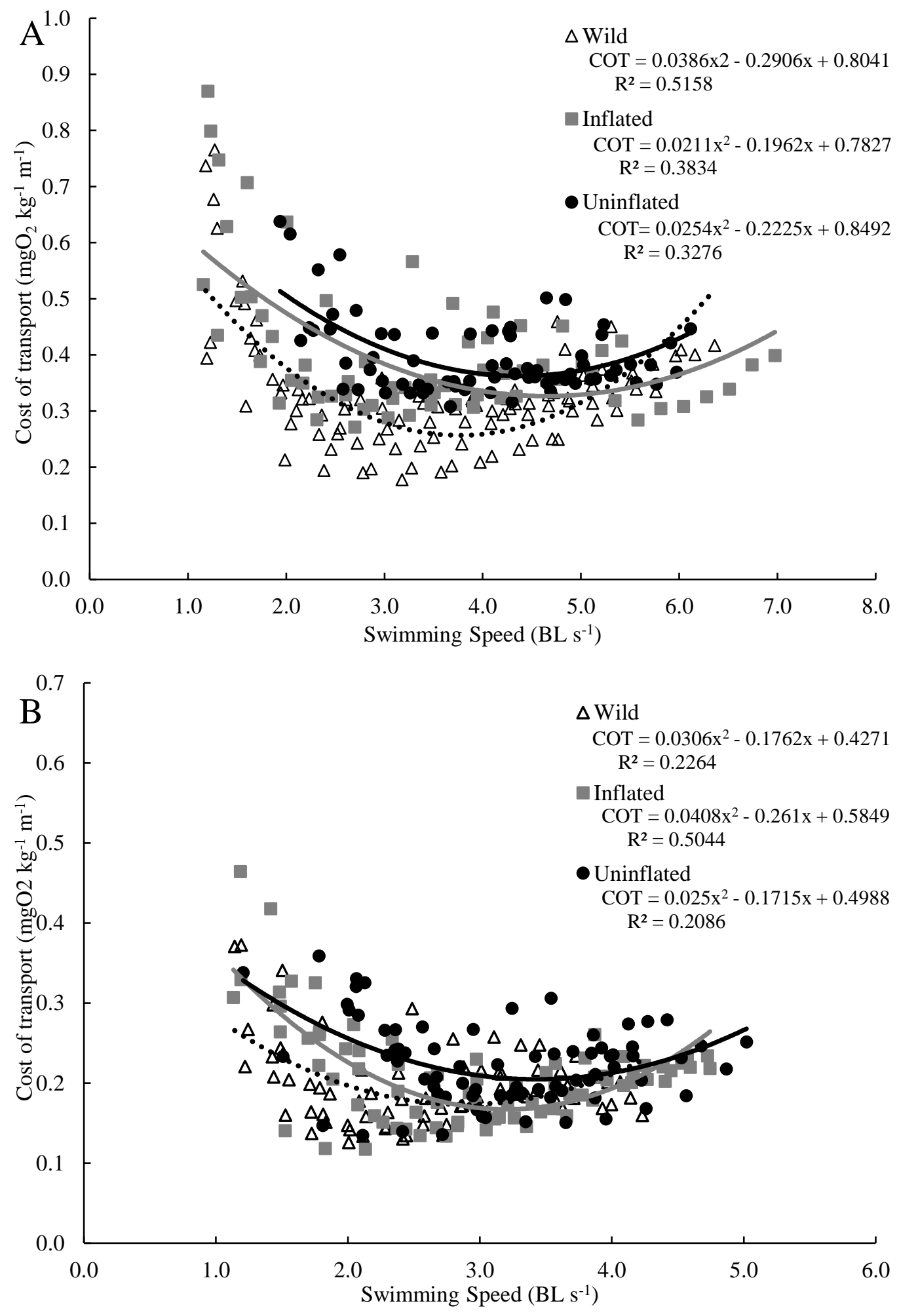


\section{Discussion}

Physiological metrics used to evaluate the growth and development of S. dorsalis demonstrated that cultured yellowtail without properly inflated swim bladders have reduced fitness (e.g., higher metabolic rates for a range of swimming speeds, slower growth, and higher FCR) compared to cultured fish with properly inflated swim bladders as well as wild-caught controls. When comparing the fitness of inflated fish to that of wild conspecifics, results indicate that there is still room for targeted improvement in the fitness of inflated fish, such as lowering FCR through improving SMR. Although the wild fish demonstrated more favorable fitness in the key areas mentioned, the fitness advantage was lost over time indicating that aquaculture rearing conditions used in this study were suboptimal for fish fitness.

The uninflated fish used in this study were negatively buoyant and denser than the other groups $\left(1.06 \mathrm{~g} \mathrm{~cm}^{-3}\right.$ vs. $\left.1.02 \mathrm{~g} \mathrm{~cm}^{-3}\right)$, which required them to swim at faster speeds in order to generate lift and maintain hydrostatic equilibrium. This was especially apparent during swim tunnel testing in which the uninflated fish had a much harder time swimming at low speeds than the other two groups, resulting in a lack of metabolic data less than $2 \mathrm{BL} \mathrm{s}^{-1}$. The observed difficulty in swimming at these low speeds is consistent with the need for negatively buoyant fish to maintain minimum speeds of $1-3 \mathrm{BL} \mathrm{s}^{-1}$ to avoid sinking (Brix, 2002; Pelster, 1997), and the shallow depth of the respirometer often necessitated even faster speeds to prevent the fish from brushing or dragging along the bottom due to their steep swimming angle needed to generate lift. This need to swim quickly 
to maintain hydrostatic lift without the buoyancy aid of a swim bladder was further supported by observations of this group continuously swimming faster than the other groups in the growout tanks. These faster swimming speeds lead to higher energetic costs (Fig. 1) and were likely the primary contributor to the higher FCR observed for the uninflated fish during growout. Although maintaining faster swimming speeds is energetically costly, it may have helped the uninflated fish retain some aspect of fitness, including the ability to reach critical swimming speeds comparable to those achieved by wild and inflated fish.

In addition to increased energetic demands due to constantly swimming at a faster speed, uninflated fish also showed differences in the relationship between oxygen consumption and swimming speed. Although the SMR of uninflated fish was not significantly different from that of the inflated fish at either size, the uninflated fish did have higher oxygen consumption than the inflated fish for swimming speeds between 2.5 and $5.3 \mathrm{BL} \mathrm{s}^{-1}$ at Size A and from 2.3 to $4.5 \mathrm{BL} \mathrm{s}^{-1}$ at Size B indicating they were less efficient swimmers over that range of speeds. This increased energy demand from more laborious swimming, likely necessitates increased food consumption without a concomitant increase in growth, further contributing to the less efficient FCR observed. Less efficient energy allocation seems to also lead to slower growth, resulting in significantly shorter FL and TL which contributed to a significantly higher condition factor as compared to the other groups. This is consistent with larval studies reporting reduced growth in several species of fish with uninflated swim bladders (Battaglene and Talbot, 1992; Chatain, 1989; Czesny et al., 2005; Hashimoto et al., 2012; Jacquemond, 
2004b; Kindschi and Barrows, 1993) and confirmed the reduced growth and physiological effects over a longer period of time that previous studies. In addition to slower growth, failure to inflate the swim bladder has been linked to spinal deformation, such as lordosis, in several species (Chatain, 1994; Jacquemond, 2004a; Woolley et al., 2014), and mild to severe lordosis was externally visible in $40 \%$ (14 of 35 ) of the uninflated fish examined at the end of the 32-week growout in this study. This resultant skeletal deformity may further affect their swimming performance, and cause subsequent developmental issues that lead to less favorable growout.

Clear differences in fitness between the wild and inflated fish in this study were evidenced by the lower SMR at Size A and more efficient feed conversion of the wild group. Similar disparities in fitness between wild-caught and hatcheryreared conspecifics have been previously reported for $S$. dorsalis (Wegner et al., in review) and are a common challenge in aquaculture for a range of species (Basaran et al., 2007; Duthie, 1987; Hammenstig et al., 2014; McDonald et al., 1998; Pedersen et al., 2008; Shustov and Shchurov, 1988). Wegner et al. found that hatchery yellowtail, produced by HSWRI, had a significantly lower critical swimming speed, higher standard metabolic rate, and smaller aerobic scope in comparison to wild-caught fish; however, in the current study there was no significant difference in critical swimming speed or aerobic scope between groups. These differences in results could be attributed to improvements in larval husbandry practices that have led to better survival, hardiness, and enhanced 
fitness of the 2015 hatchery cohort used in this study compared to the 2012 cohort used in Wegner et al. (Kevin Stuart, personal communication).

Although changes to larval production protocols for S. dorsalis have shown positive effects on the fitness of hatchery fish, the results from this study shed light on areas in which improvement is still needed. Although the inflated fish had a significantly greater final body mass and girth, they had a poorer feed conversion than the wild fish. Their superior growth performance could be attributed to greater food consumption with the inflated fish eating $28.2 \%$ more food than the wild fish, however they only gained $21.2 \%$ more mass. This resulted in a higher feed conversion ratio in the inflated fish of 1.49 vs. 1.41 for wild fish, equating to more food necessary to gain equivalent mass. The better efficiency of the wild fish may have been a result of a lower SMR, and significantly lower minimum cost of transport when they were initially brought into captivity (Size A). This suggests that improving metabolic fitness in aquaculture-reared fish may be beneficial for feed efficiency, and since aquaculture feed is the largest operational expense for commercial farms, improved feed conversion could have major financial implications that make this an important area for further investigation and optimization.

The degradation of fitness observed in the wild fish over time likely indicates inefficiency in the rearing and growout process used in this study, which means there is opportunity to improve rearing protocols to extend fitness benefits and potentially produce more efficient and healthier fish. In the wild, fish may encounter strong current regimes in addition to needing to search for prey and 
avoid predators, activities that likely help to improve and maintain fitness that fish do not experience in captivity. Removing wild fish from a more active environment seems to contribute to their reduced fitness advantage at Size B after 4 months in captivity, and suggests a need for exercise for this species in aquaculture. Research involving sustained exercise has shown positive effects on growth (Davison and Goldspink, 1977; Ibarz et al., 2011; Palstra et al., 2015; Totland et al., 1987; Walker and Emerson, 1978), and behavior (Adams et al., 1995; Christiansen and Jobling, 1990; East and Magnan, 1987) of several species, although a majority of work in this area has focused on salmonids, and more research is needed on other active species such as $S$. dorsalis. The limited work on Seriola spp. suggests improved growth and feed conversion associated with exercise training (Brown et al., 2011; Palstra et al., 2015; Peters, 2009; Yogata and Oku, 2000); however, it is not known if and for how long these benefits persist once exercise is completed. The duration of beneficial responses could be critical for determining at what point exercise should be introduced in the rearing process and how much exercise is necessary to elicit a lasting response. Further research on protocols that could improve and prolong periods of metabolic fitness could greatly benefit commercial producers of $S$. dorsalis and like species.

\section{Conclusions}

While fish with uninflated swim bladders were comparable to the other groups in some metrics of fitness, such as critical swimming speed, their need to swim at higher speeds in growout tanks, slower growth, and poor FCR call into question the sustainability of rearing fish with this deformity. These measures of 
growth and growth efficiency, in addition to visible deformities (e.g. lordosis) that would likely reduce market price, indicate that uninflated fish are not economical to rear for commercial production. In addition, this study suggests the fitness of inflated fish could be improved through lowering their standard metabolic rates which could in turn improve feed conversion. This could potentially be achieved through exercise, as limited prior research on S. dorsalis has shown promising links between sustained exercise and improved feed conversion, which has significant implications for commercial production. Although wild fish proved to be more fit in key areas as demonstrated by their lower FCR and SMR, their fitness advantage was not retained with time in captivity, illuminating the need for more effective rearing protocols that can enhance fitness and improve development. 


\section{CHAPTER 3: EXERCISE STUDY}

\section{Introduction}

The carangid genus Seriola is composed of active, fast growing fishes that are targets for continued aquaculture development due to their adaptability to a culture environment and high market value (Nakada, 2008). Several Seriola species are farmed globally (e.g., S. quinqueradiata in Japan and Korea; S. dumerili in Japan, the Mediterranean and Vietnam; and S. lalandi in Southern Australia and New Zealand) and there is a push for development of S. dorsalis in US waters. S. dorsalis was recently distinguished as a unique species from S. lalandi (Martinez-Takeshita et al., 2015), and is well adapted to its cool regional habitat that can range from Mazatlán, Mexico to Southern Washington State (Baxter, 1960). While captive rearing of S. lalandi has been occurring in some countries for over 70 years (Nakada, 2008), rearing S. dorsalis in captivity is a nascent industry, and differences in the genetic and physiological makeup of S. dorsalis may influence growth and development in significant ways. This underscores the need for further research in order to craft species-specific rearing protocols.

Recent work has found that hatchery-reared $S$. dorsalis have reduced fitness in comparison to wild-caught conspecifics (See Chapter 2; Wegner et al., in review), which is consistent with findings for several other aquaculture species (Basaran et al., 2007; Duthie, 1987; Hammenstig et al., 2014; McDonald et al., 1998; Pedersen et al., 2008; Shustov and Shchurov, 1988). Metrics of 
physiological fitness such as metabolic rate, critical swimming speed, growth rate, and feed conversion, are important for understanding fish health and development, and can help identify areas for targeted, species-specific improvements in aquaculture. Results from previous studies using such metrics, indicate that although hatchery-reared S. dorsalis grow well in land-based culture (see Chapter 2), they can have higher standard metabolic rates, slower critical swimming speeds (Wegner et al., in review), and less efficient feed conversion ratios (see Chapter 2) than wild-caught counterparts. Such reduced fitness and efficiency could have significant negative impacts on production when scaled up to a commercial level.

One possibility for improving the fitness of hatchery-reared S. dorsalis is through the use of sustained exercise training, which is a promising non-invasive and non-hormonal treatment that has been shown in other fish species to stimulate growth (Brown et al., 2011; Christiansen et al., 1989; Davison and Goldspink, 1977; Palstra et al., 2015; Totland et al., 1987; Yogata and Oku, 2000), improve feed conversion (Christiansen et al., 1992; Davison and Goldspink, 1977; East and Magnan, 1987; Jørgensen and Jobling, 1993; Yogata and Oku, 2000), reduce aggressive behavior (Adams et al., 1995; Christiansen and Jobling, 1990; Jørgensen and Jobling, 1993), and potentially affect metabolism (Bagatto et al., 2001; Brown et al., 2011; Skov et al., 2011). However, the presence and magnitude of most responses appear to be species-specific, and dependent on the intensity and duration of exercise, the life stage of the fish, and environmental conditions such as temperature. The majority of previous work has generally used 
periods of sustained exercise on the order of four weeks to several months (Brown et al., 2011; Herbert et al., 2011; Totland et al., 1987). However, recent work on S. lalandi by Palstra et al. (2015) showed that a mere 18-day exercise regime resulted in enhanced growth and feed conversion comparable to longer exercise studies, but it remains generally unknown if such short durations of sustained swimming can regularly elicit such benefits. It is also poorly understood for how long any benefits persist post-exercise since most previous work has only examined responses immediately following completion of the exercise training. Of the limited work evaluating the persistence of beneficial changes, Young and Cech Jr. (1994) found that young-of-the-year Striped Bass (Morone saxatilis) exercised at 1.5-2.4 $\mathrm{BL} \mathrm{s}^{-1}$ for 60 days, remained significantly larger than the control group for the entire 56-day post-exercise growout period examined.

In addition to a limited understanding of the duration of exercise needed to elicit growth and health benefits and the persistence of such benefits post exercise, other factors such as the life stage, or timing of exercise within the rearing process, has potential to affect the magnitude of the growth response. Phenotype can be influenced by the interaction of environmental factors and a fish's genotype, and sensitivity to environmental stimuli changes throughout development (Rezende et al., 2005; Spicer and Burggren, 2003). During early ontogeny, muscle development occurs so rapidly that some changes become irreversible (Johnston, 2006; Rezende et al., 2005) and there may be opportunity to create a lasting response in the musculature via exercise if it is introduced early in the rearing process. Changes to the musculature, such as stimulated 
hypertrophy and a potential increase in hyperplasia in response to exercise could result in better growth (see Johnston 1999, and Davison 1997 for review), but the optimal developmental stage for introducing exercise is still uncertain.

This study seeks to assess the duration of exercise necessary to elicit a positive growth and physiological response in $S$. dorsalis, and evaluate the persistence of that response, through tracking the fitness of fish subjected to exercise of equal intensity but varying duration. S. dorsalis used in this study were thus exercised continuously for two, three, or four weeks in custom-built raceways designed to encourage sustained exercise, and then removed for a 24week growout period during which several metrics of physical fitness were monitored in comparison to non-exercised controls. In addition, exercise was introduced at an early life stage (approx. $4 \mathrm{~g}$ and $7 \mathrm{~cm} \mathrm{TL}$ ) in comparison to previous work done with larger S. lalandi (Brown et al., 2011; Palstra et al., 2015). Improving fitness of hatchery-reared S. dorsalis through exercise could not only benefit the health and wellbeing of the fish, but also inform more costeffective growout procedures and enhance production through accelerated growth and more efficient feed conversion.

\section{Methods}

\section{Experimental Fish}

Aquaculture-reared California Yellowtail, S. dorsalis, produced by HubbsSeaWorld Research Institute (HSWRI, San Diego, CA), were transferred to the experimental aquarium facility at the Southwest Fisheries Science Center 
(SWFSC, La Jolla, CA) at approximately 45 days post hatch. Fish were allowed to recover from transfer stress for a minimum of one week before any experimentation began, at which point they had resumed normal eating and swimming behavior for several days. All experimentation was done according to the SWFSC Institutional Animal Care and Use Committee approved protocol \#SW1602.

\section{$\underline{\text { Exercise Protocol }}$}

In order to get a better understanding of the duration of exercise necessary to elicit a positive growth and physiological response, three exercise regimes were employed in comparison to a non-exercised control group. Exercised fish swam continuously for two weeks $(2 \mathrm{~W})$, three weeks $(3 \mathrm{~W})$, or four weeks $(4 \mathrm{~W})$ in custom designed raceways (Figure 2.1 and Figure 2.2; Oceans Design, Colorado Springs, CO) that consisted of a linear working section $(165 \times 20 \times 23 \mathrm{~cm})$ with a clear acrylic side wall, to allow observation of swimming behavior. Raceways were placed on a metal frame above a sump that contained four 100-micron bag filters to collect solids. A 3-phase induction motor (Teco Westinghouse Motor Company, Round Rock, TX) circulated water between each sump and the corresponding raceway, and a Matala filter pad and flow straighteners at the front of the working section helped to streamline water flow that traveled to the standpipe at the opposite end. Mesh fencing at the front and back of the working section kept the fish contained and prevented fish from traveling down into the sump. Individual motors and interchangeable stand pipes allowed for manipulation of flow speed and water volume of each raceway. All tanks and 
equipment were supplied with flow-through filtered seawater drawn from the end of the Scripps Institution of Oceanography pier in La Jolla, CA and supplied at a rate of approximately $15 \mathrm{~L} \mathrm{~min}^{-1}$ to each raceway. Water temperature in all raceways was maintained at $22.5 \pm 0.5^{\circ} \mathrm{C}$.

At the start of the experiments, fish were lightly anaesthetized using MS222 (tricane methanesulphonate, $80 \mathrm{mg} \mathrm{L}^{-1}$ ) and a representative subset of experimental fish $(\mathrm{n}=98)$ were measured for body length $(\mathrm{BL},=$ total length, 7.05 $\pm 0.71 \mathrm{~cm}$, mean \pm standard deviation), fork length $(\mathrm{FL}, 6.39 \pm 0.68 \mathrm{~cm})$, and body mass ( $4.35 \pm 1.26 \mathrm{~g})$, before all fish were evenly distributed into three raceways ( $n=145$ each raceway), and a control tank $(n=145)$. Fish were placed in the raceways with the lowest flow allowed by the pumps (under approximately 4 $\mathrm{BL} \mathrm{s}^{-1}$ ) that was gradually increased over several hours to a speed of $61.6 \pm 3.2$ $\mathrm{cm} \mathrm{s}^{-1}$ (around 8.7 $\mathrm{BL} \mathrm{s}^{-1}$ ). This speed was determined based on work by Palstra et al (2015) and Schwebel et al. (see Chapter 2) that used cost of transport to determine optimal swimming speed $\left(U_{\mathrm{opt}}\right)$ for $S$. lalandi and $S$. dorsalis respectively. Flow was checked daily using a cylindrical vane wheel flow meter probe (Höntzsch Gmbh, Waiblingen, Germany) and was adjusted accordingly to maintain optimal speed for a given body length as the fish grew. Once exercise was complete, fish were removed from the raceways and placed in separate oval growout tanks that were identical to the control tank (304 x 154 x $80 \mathrm{~cm}$, volume $\left.=3.34 \mathrm{~m}^{3}\right)$. 


\section{Growth and Feed Conversion}

A 24-week growout period was used to evaluate the effect of exercise duration on growth over time. Somatic measurements (BL, FL, and mass) were taken at the start of growout before exercise began and again after two weeks, three weeks and four weeks had elapsed (when each exercise regime was completed), and then every two weeks thereafter until the end of the six-month growout period (14 time-points total). For each measurement, a subset of 30 fish from each treatment group were randomly selected, anaesthetized and measured. Following measurements, fish recovered quickly and generally resumed normal swimming and feeding behavior within a few hours. In addition to using somatic measurements to evaluate growth, condition factor (CF) for each fish was calculated using:

$$
\mathrm{CF}=\left(\mathrm{M} / \mathrm{BL}^{3}\right) \times 100
$$

where $\mathrm{M}$ is fish mass $(\mathrm{g})$ and $\mathrm{BL}$ is total length in $(\mathrm{cm})$.

Water temperature $\left(22.1 \pm 0.3^{\circ} \mathrm{C}\right)$ and other parameters (e.g., dissolved oxygen, stocking density, and water quality) were monitored daily and kept consistent between growout tanks. Water was supplied to each tank at a rate of

approximately $23 \mathrm{~L} \mathrm{~min}^{-1}$, and spray bars were used to created directional flow.

Fish were initially fed Otohime marine fish larval and weaning feed (Marubeni Nisshin Feed Co., Ltd, Tokyo, Japan) for approximately 11 weeks before transitioning to EWOS commercial pellets (EWOS, Surrey, BC, Canada) for the remainder of the growout. Fish were hand fed to satiation three to five 
times daily seven days a week during the exercise period (first four weeks of experimentation), and six days a week thereafter. Feed conversion ratio (FCR) was calculated from the 20 weeks of data collected after all exercise was complete using:

$$
\mathrm{FCR}=\frac{\text { total dry feed consumed }(\mathrm{g})}{\text { total weight gained }(\mathrm{g})}
$$

Feed consumption data collected during exercise could not be included in FCR calculations due to high flow speeds causing an unmeasurable amount of feed to pass by the fish during feedings.

\section{$\underline{\text { Respirometry }}$}

In order to compare the effect of exercise on metabolic performance, respirometry was conducted on each group at three sizes during the growout period. For all respirometry trials, fish were randomly selected from each group $(2 \mathrm{~W}, 3 \mathrm{~W}, 4 \mathrm{~W}$, and control; $\mathrm{n}=8$ for each group at each size point), and fasted for approximately 24 hours before testing began. The first respirometry trials were conducted within the week following completion of exercise (Size A), and as such were staggered as fish completed either two weeks, three weeks, or four weeks of continuous exercise. During testing the $2 \mathrm{~W}$ group was $32.1 \pm 11.0 \mathrm{~g}$ and $13.7 \pm$ $1.4 \mathrm{~cm} \mathrm{BL}$, the $3 \mathrm{~W}$ group was $53.9 \pm 13.2 \mathrm{~g}$ and $16.1 \pm 1.3 \mathrm{~cm} \mathrm{BL}$, and the $4 \mathrm{~W}$ group was $87.7 \pm 12.2 \mathrm{~g}$ and $18.9 \pm 0.9 \mathrm{~cm} \mathrm{BL}$. Respirometry of control fish was interspersed with testing of the exercised groups $(41.1 \pm 18.3 \mathrm{~g}$ and $14.9 \pm 2.2 \mathrm{~cm}$ BL). Subsequent respirometry was conducted when fish were $204.3 \pm 53.8 \mathrm{~g}$ and $25.1 \pm 2.0 \mathrm{~cm} \mathrm{BL}($ Size B), and again when fish were 409.1 $\pm 62.0 \mathrm{~g}$ and $31.9 \pm$ 
1.4 cm BL (Size C). Trials at Size A were done using a 5.4 L variable speed Brettstyle swim tunnel respirometer with a $30 \times 7.5 \times 7.5 \mathrm{~cm}$ working section, while testing at Size B and Size C used a 29.6 L respirometer with a 55 x 14 x $14 \mathrm{~cm}$ working section (Loligo Systems, Viborg, Denmark). Testing was limited to sizes where fish could comfortably fit in the working section of the swim tunnel and successfully complete the swimming regime.

Both respirometers used were of the same design and supplied with filtered seawater at approximately $22{ }^{\circ} \mathrm{C}$, consistent with the rearing temperature. The respirometers were submerged in buffer tanks of seawater and the inflows and outflows were controlled with manual valves. Prior to experimentation, water flow velocity within the swim tunnel was calibrated with a cylindrical vane wheel flow meter probe as described in Chapter 2. Fish were acclimated to the respirometer for a minimum of one hour at a low flow speed (typically under 40 $\mathrm{cm} \mathrm{s}^{-1}$ ), and acclimation began once the fish was swimming steadily with a regular gait. Following acclimation, fish were made to swim against a predetermined flow speed and the system was sealed to measure oxygen level (as $\%$ air saturation) using a Fibox 3 fiber optic oxygen transmitter and temperature probe (PreSens Precision Sensing GmbH, Regensburg, Germany). Saturation was logged every five seconds using PreSense software version PST3v602. The fish was allowed to draw the oxygen saturation down from $100 \%$ to $80 \%$ before the system was flushed with fresh seawater and the flow speed was raised by $10 \mathrm{~cm}$ $\mathrm{s}^{-1}$. Approximately two minutes after an increase in speed, the respirometer was sealed and this process was repeated for a minimum of eight swimming speeds. If 
time allowed, some measurements were duplicated at a given swimming speed, and in this case the resulting traces were averaged to find the mean metabolic rate $\left(\mathrm{MO}_{2}\right)$ at that speed. After each swimming trial was concluded, the fish was removed, and the respirometer was resealed to measure background respiration, which was subtracted from the fish's calculated $\mathrm{MO}_{2}$. Fish were then sacrificed using an overdose of MS-222 (800 mg L $\left.{ }^{-1}\right)$, and measured [BL, FL, body mass, and girth].

Following experimentation, swimming speed was corrected for the solid blocking effect of both the flow meter used for calibration, and for the effect of each fish in the chamber according to the methods described in Chapter 2. Mean water temperature for all trials was $22.1 \pm 0.3{ }^{\circ} \mathrm{C}$; however, temperature ranged from 20.8 to $23.4{ }^{\circ} \mathrm{C}$, so for direct comparison between groups, metabolic data were corrected to a temperature of $22.0^{\circ} \mathrm{C}$ using $Q_{10}=2$ (Pirozzi and Booth, 2009).

For each fish, oxygen consumption was plotted against swimming speed, and the resulting graph showed a check mark shaped curve (characteristic of many pelagic fishes), due to increased energy costs associated with maintaining hydrostatic equilibrium at low speeds (Webb, 1998). Data points from the low swimming speeds that were higher than the vertex of the curve were therefore removed before group data was combined (Sepulveda et al., 2003). In order to be directly comparable within a size point, metabolic data for each fish were scaled to a body mass of $55 \mathrm{~g}$ at Size A, $205 \mathrm{~g}$ at Size B, and $410 \mathrm{~g}$ at Size C using mass $^{0.80}$ (Brett and Groves, 1979). 


\section{$\underline{\text { Statistical Analysis }}$}

Somatic measurements and condition factor at each sampling point were compared statistically across groups using a single factor ANOVA, followed by a Tukey post-hoc test if $P \leq 0.05$. Data are presented as the mean \pm standard deviation.

In addition, growth (in body lengths) for each group was analyzed using a von Bertalanffy growth model (VBGM) based on the equation:

$$
L_{\mathrm{t}}=L_{\infty} *\left(1-\mathrm{e}^{-K^{*}\left(t-t_{0}\right)}\right)
$$

in which $L_{\mathrm{t}}$ is length-at-age, $L_{\infty}$ is the asymptotic length, $K$ is the Brody growth coefficient, and $t_{0}$ is the age where length is 0 (Ricker, 1975). We used model selection (Burnham and Anderson, 2002) to evaluate whether $L_{\infty}, K$, or $t_{0}$ varied among treatments. Specifically, we established a set of 8 a priori models in which each variable was either static or variable among treatments (Table 2.1). Residuals of the full model $\left(L_{\infty}, K\right.$, or $\left.t_{0}\right)$ indicated that assumptions of normality were met. Model fit was assessed based on maximum likelihood using Akaike's information criterion (AIC) scores. In cases where AIC scores differed by 2 or less and models were nested (i.e., contained common variables), ANOVAs were used to determine if the models differed. If the ANOVA $p$-value was greater than 0.05 we considered the models to be equivalent and parsimoniously regarded the one with fewest parameters as the best-fit model (Ogle, 2013). VBGM were created and evaluated using the FSA (Ogle 2017), FSAdata (Ogle 2017), and nlstools (Baty et al., 2015) packages in R version 3.3.2 (R Core Development 
Team 2016). As the best model had one variable that varied among treatments ( $K$; see Results), we used Welch modified two-sample t-tests based on summary statistics (i.e., slope and se estimates) to evaluate which treatments differed from one another using the R package BSDA (Arnholt, 2012).

Scaled metabolic data were compared by performing a bootstrap analysis in RStudio in which 10,000 exponential regression replicates of the relationship between oxygen consumption and swimming speed were created for each group. Each regression line was then extrapolated to a swimming speed of $0 \mathrm{~cm} \mathrm{~s}^{-1}$ and results for each group were averaged to calculate the SMR. Significance was determined if less than $5 \%$ of resultant regressions lines overlapped at a swimming speed of zero. 
Table 2.1. Description of a priori models used to evaluate the variables $\left(L_{\infty}, t_{0}, K\right)$ for the best fit of the von Bertalanffy growth model. 


\begin{tabular}{|c|c|c|}
\hline No. & Model Name & Description \\
\hline 1 & fitCom & All varables are the same across groups (constant) \\
\hline 2 & fit1LK & $\begin{array}{l}\text { Both the } K \text { and L } \infty \text { parameters vary across group but } \\
\text { t } 0 \text { is constant }\end{array}$ \\
\hline 3 & fit1KT & $\begin{array}{l}\text { Both the } t 0 \text { and } K \text { parameters vary across groups and } \\
\text { Lo is kept constant }\end{array}$ \\
\hline 4 & fit1LT & $\begin{array}{l}\text { Both the } t 0 \text { and L } \infty \text { parameters vary across groups } \\
\text { and } \mathrm{K} \text { is kept constant }\end{array}$ \\
\hline 5 & fit $2 \mathrm{~T}$ & $\begin{array}{l}\text { Only t0 varies across groups, both } \mathrm{K} \text { and L } \infty \\
\text { parameters kept constant }\end{array}$ \\
\hline 6 & fit $2 K$ & Only K varies across groups, t0 and L $\infty$ kept constant \\
\hline 7 & fit $2 \mathrm{~L}$ & $\begin{array}{l}\text { Only L } \infty \text { varies across groups, both t0 and } \mathrm{K} \\
\text { parameters kept constant }\end{array}$ \\
\hline 8 & fitGen & All parameters vary across groups \\
\hline
\end{tabular}


Figure 2.1. Side view (A) and top view (B) of custom-built raceways designed for sustained exercise training. 


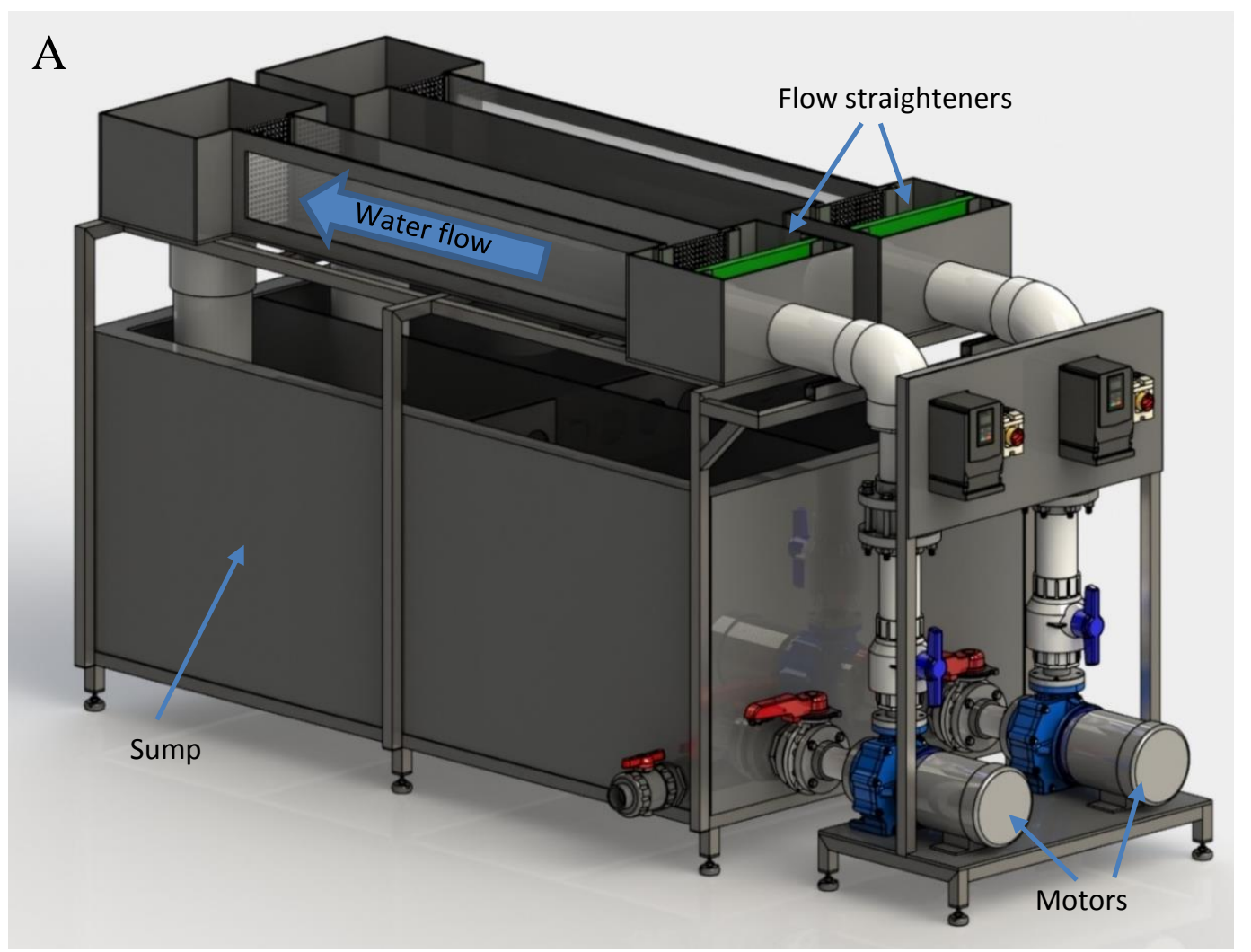

B

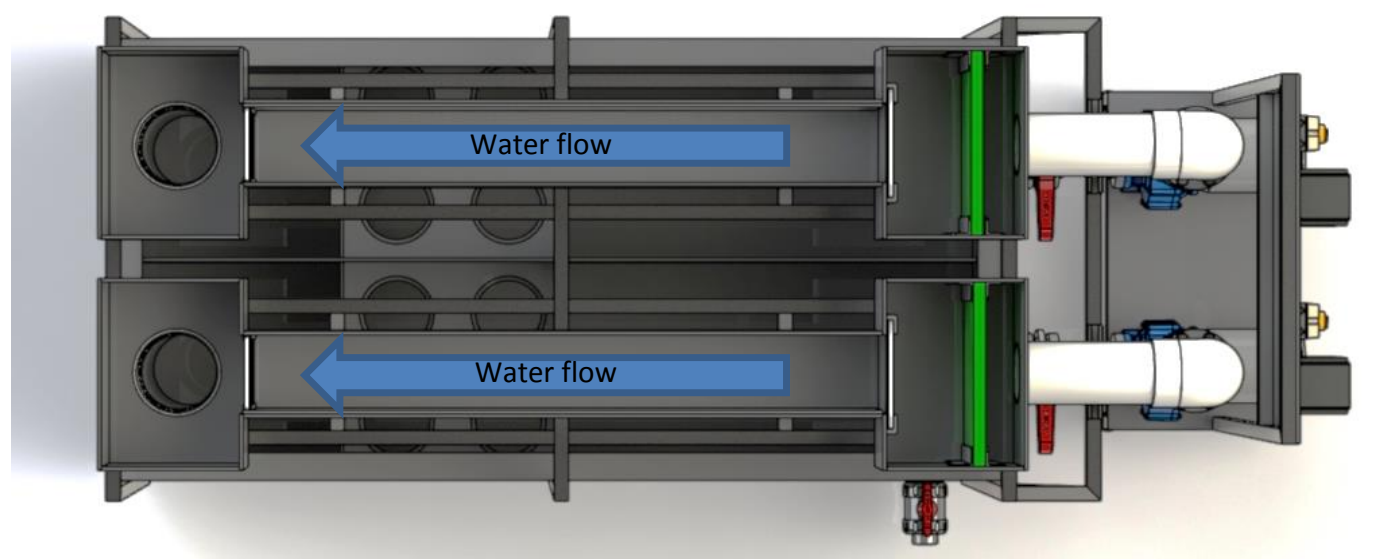


Figure 2.2. Juvenile California Yellowtail (S. dorsalis) swimming in custom-built raceways designed to encourage sustained exercise. 


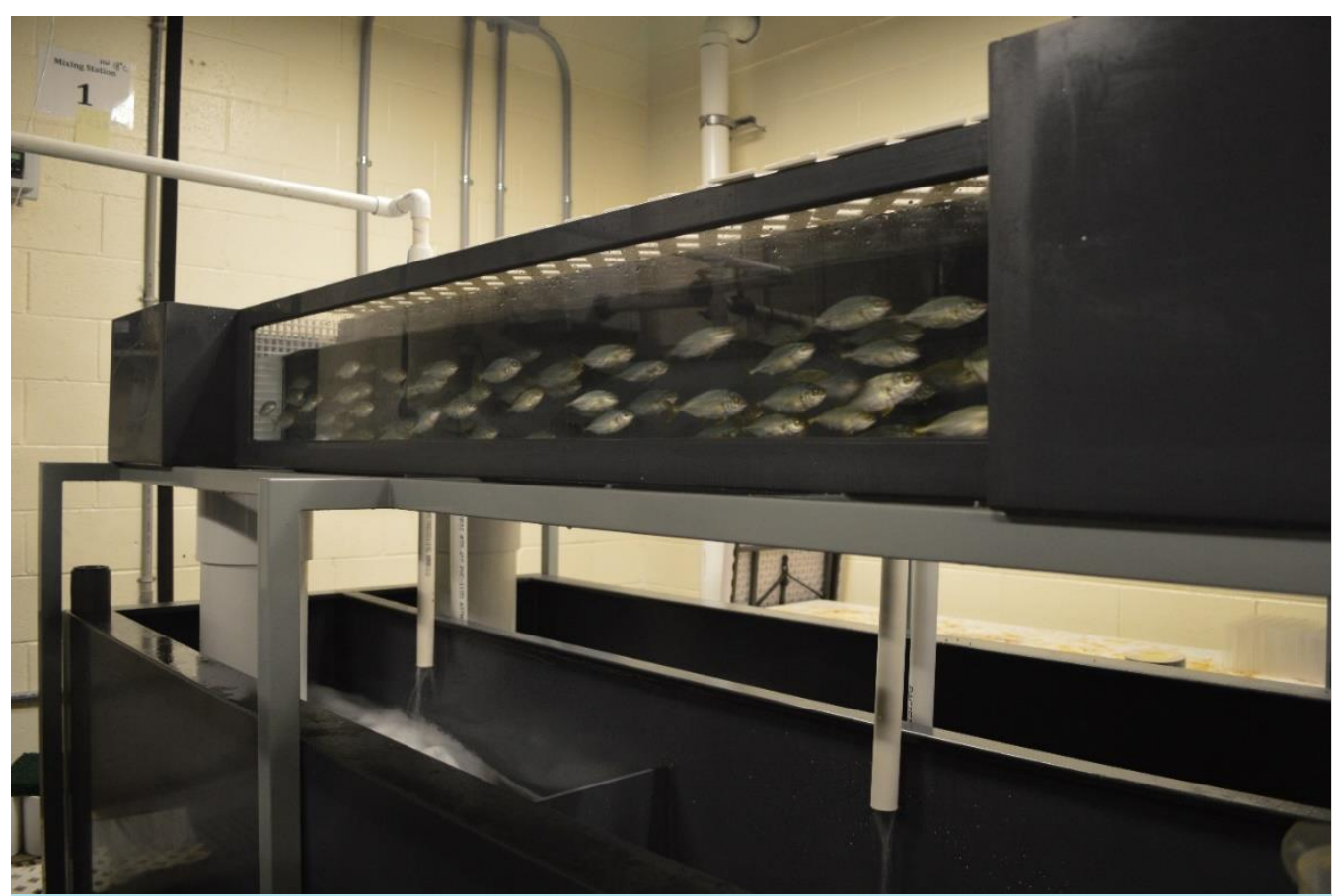




\section{Results}

\section{Growth and Feed Conversion}

At the start of the study fish were $4.35 \pm 1.26 \mathrm{~g}$ and $7.05 \pm 0.71 \mathrm{~cm} \mathrm{BL}$. Figure 2.3 shows the percent difference in mass of each exercised group from the control over the course of the 24-week growout period. Group $4 \mathrm{~W}$ had approximately $35 \%$ greater mass than the control group immediately following exercise at week four (reflecting a 37\% growth improvement over the control group), and retained a significantly larger mass for twelve weeks post exercise. The $2 \mathrm{~W}$ and $3 \mathrm{~W}$ groups had significantly larger mass than the control group from 6-8 weeks post-exercise, and from 6-12 weeks post-exercise respectively. However, there was a clear declining trend in this growth advantage for all exercised groups during the growout period (Figure 2.3), and there were no significant differences in mass between any groups beyond the sixteenth week of growout. Although the final somatic parameters after the 24-week growout were not significantly different (Table 2.2$)$, the exercised groups (2W, $3 \mathrm{~W}$ and $4 \mathrm{~W})$ had $5.3 \%, 8.3 \%$, and $8.7 \%$ greater mass than the control group, respectively.

Fork length data compared using von Bertalanffy growth models are shown in Figure 4. The general model, the model with variable L and K, and the models with just variable L or K had AIC values that were separated by less than 2 (Table 2.3). There was no support for models that did not include either variable L or variable $\mathrm{K}$. ANOVAs indicated that there were no differences between the general and variable $\mathrm{K}$ models $(\mathrm{F}=1.9, \mathrm{p}=0.7)$ or between variable $\mathrm{K}$ and variable $\mathrm{K}$ and $\mathrm{L}$ models $(\mathrm{F}=2.4, \mathrm{p}=0.7)$. There was, however, $\mathrm{a}$ 
difference between the model with variable $\mathrm{L}$, and variable $\mathrm{K}$ and $\mathrm{L}(\mathrm{F}=2.6$, $p=0.05$ ), suggesting that the model with variable $K$ and $L$ better described the data than the one with just variable $\mathrm{L}$. Based on the principle of parsimony, we considered the variable $\mathrm{K}$ model to best fit the data (model 6, Table 2.3). Model parameter comparisons using t-tests revealed that the $4 \mathrm{~W}$ group had a significantly higher $K$ than the control and $2 \mathrm{~W}$ groups, but did not differ significantly from the $3 \mathrm{~W}$ group. Model parameters are summarized in Table 2.4 and t-tests in Table 2.5 .

Although the nature of FCR data did not allow for the testing of statistical differences between groups (FCR estimates were based on group feed and growth rates; individual fish growth and feed consumption were not tracked), FCR showed little variance between groups. FCR was 1.16 for the $2 \mathrm{~W}$ group, 1.17 for the $3 \mathrm{~W}$ group, 1.19 for the $4 \mathrm{~W}$ group, and 1.20 for the control group (Table 2.2).

$\underline{\text { Metabolic Data }}$

SMRs for each exercised group at each of the three measured sizes (adjusted to a temperature of $22^{\circ} \mathrm{C}$ ) are summarized in Table 2.6. There were no significant differences in SMR between any of the groups for Size A or Size B; however, the $2 \mathrm{~W}$ group had a significantly higher SMR at Size C (Figure 2.5). Although not statistically significant, the SMRs at Size A for 2W $(5.05 \pm 0.83$ $\left.\mathrm{mgO}_{2} \mathrm{~kg}^{-1} \mathrm{~min}^{-1}\right), 3 \mathrm{~W}\left(4.96 \pm 0.61 \mathrm{mgO}_{2} \mathrm{~kg}^{-1} \mathrm{~min}^{-1}\right)$, and $4 \mathrm{~W}\left(4.78 \pm 0.64 \mathrm{mgO}_{2}\right.$ $\left.\mathrm{kg}^{-1} \mathrm{~min}^{-1}\right)$ were $9.6 \%, 11.3 \%$, and $14.5 \%$ lower than the control $(5.59 \pm 0.30$ $\left.\mathrm{mgO}_{2} \mathrm{~kg}^{-1} \mathrm{~min}^{-1}\right)$, respectively. 
Table 2.2. Final somatic measurements and FCR for each experimental group at the end of the 24-week growout period. At the start of experimentation, fish were $6.39 \pm 0.68 \mathrm{~cm} \mathrm{FL}, 7.05 \pm 0.71 \mathrm{~cm} \mathrm{BL}, 4.35 \pm 1.26 \mathrm{~g}$, and had a CF of $1.20 \pm$ 0.07 . 


\begin{tabular}{lccccc}
\hline & $\begin{array}{c}\text { Fork Length } \\
(\mathbf{c m})\end{array}$ & $\begin{array}{c}\text { Body Length } \\
(\mathbf{c m})\end{array}$ & Mass $(\mathbf{g})$ & $\begin{array}{c}\text { Condition } \\
\text { Factor }\end{array}$ & FCR \\
\hline Control & $35.41 \pm 1.95$ & $39.72 \pm 2.19$ & $745.67 \pm 150.11$ & $1.17 \pm 0.09$ & 1.20 \\
$\mathbf{2 W}$ & $35.32 \pm 2.66$ & $39.72 \pm 3.08$ & $784.97 \pm 221.81$ & $1.22 \pm 0.11$ & 1.16 \\
$\mathbf{3 W}$ & $35.79 \pm 2.10$ & $40.24 \pm 2.42$ & $807.20 \pm 190.95$ & $1.22 \pm 0.09$ & 1.17 \\
$\mathbf{4 W}$ & $35.82 \pm 1.69$ & $40.25 \pm 1.94$ & $810.30 \pm 128.22$ & $1.23 \pm 0.06$ & 1.19 \\
\hline
\end{tabular}


Table 2.3. Model selection results for von Bertalanffy analysis of the effect of exercise on growth of the total length of California Yellowtail (Seriola dorsalis). The chosen best-fit model based on ANOVA results and the principle of parsimony indicated in bold. 


\begin{tabular}{cccc}
\hline Candidate model & Model No. & AIC & $\Delta$ AIC \\
\hline fit1LK & 2 & 6624.731 & 0 \\
fit2K & $\mathbf{6}$ & $\mathbf{6 6 2 5 . 8 2 4}$ & $\mathbf{1 . 0 9 3}$ \\
fitGen & 8 & 6626.113 & 1.382 \\
fit2L & 7 & 6626.446 & 1.715 \\
\hline
\end{tabular}


Table 2.4. Estimates of von Bertalanffy growth model parameters for $S$. dorsalis subjected to continuous exercise $(2 \mathrm{~W}, 3 \mathrm{~W}, 4 \mathrm{~W})$ compared to a non-exercised control group. Standard error $(\sigma)$ included for each parameter. *Used to indicate that $4 \mathrm{~W}$ was significantly greater than the Control and $2 \mathrm{~W}$, but no other significant differences were found. 


\begin{tabular}{lcccccc}
\hline & $\boldsymbol{L}_{\infty}$ & $\boldsymbol{\sigma} \boldsymbol{L}_{\infty}$ & $\boldsymbol{t}_{\mathbf{0}}$ & $\boldsymbol{\sigma \boldsymbol { t } _ { \mathbf { 0 } }}$ & $\boldsymbol{K}$ & $\boldsymbol{\sigma} \boldsymbol{K}$ \\
\hline Control & 40.95 & 0.22 & 39.36 & 0.24 & 0.01107 & 0.000155 \\
$\mathbf{2 W}$ & 40.95 & 0.22 & 39.36 & 0.24 & 0.01111 & 0.000156 \\
$\mathbf{3 W}$ & 40.95 & 0.22 & 39.36 & 0.24 & 0.01129 & 0.000160 \\
$\mathbf{4 W}$ & 40.95 & 0.22 & 39.36 & 0.24 & $0.01156^{*}$ & 0.000165 \\
\hline
\end{tabular}


Table 2.5. Results of Welch two-sample t-tests comparing values of $\mathrm{K}$ from the best fit-model results among treatment groups (Control, 2W, 3W, and 4W). 


\begin{tabular}{lcc}
\hline Groups Compared & $\mathbf{t}$ & $\mathbf{p}$ \\
\hline 4W vs. control & 2.15 & 0.03 \\
4W vs. 2W & 1.98 & 0.048 \\
4W vs. 3W & 1.16 & 0.25 \\
3W vs. control & 0.99 & 0.32 \\
3W vs. 2W & 0.82 & 0.41 \\
2W vs. control & 0.17 & 0.87 \\
\hline
\end{tabular}


Table 2.6. Standard metabolic rate for $S$. dorsalis subjected to continuous exercise $(2 \mathrm{~W}, 3 \mathrm{~W}, 4 \mathrm{~W})$ compared to a non-exercised control group at three different sizes. For direct comparison between groups, SMR data for individual fish were adjusted to a temperature of $22{ }^{\circ} \mathrm{C}$ using $Q_{10}=2$, and scaled to $55 \mathrm{~g}$ at Size A, $205 \mathrm{~g}$ at Size B, and $410 \mathrm{~g}$ at Size C using mass ${ }^{0.80}$. Significant difference indicated in bold. 


\begin{tabular}{lccc}
\hline & $\begin{array}{c}\text { SMR Size A } \\
\left(\mathbf{m g O}_{\mathbf{~ k g}} \mathbf{~ m i n}^{-1}\right)\end{array}$ & $\begin{array}{c}\text { SMR Size B } \\
(\mathbf{m g O 2} \mathbf{~ k g - 1} \text { min-1 })\end{array}$ & $\begin{array}{c}\text { SMR Size C } \\
(\mathbf{m g O 2} \mathbf{~ k g - 1 ~} \mathbf{m i n}-1)\end{array}$ \\
\hline Control & $5.59 \pm 0.30$ & $3.22 \pm 0.38$ & $2.00 \pm 0.18$ \\
$\mathbf{2 W}$ & $5.05 \pm 0.83$ & $3.70 \pm 0.41$ & $\mathbf{3 . 3 6} \pm \mathbf{0 . 4 0}$ \\
$\mathbf{3 W}$ & $4.96 \pm 0.61$ & $3.74 \pm 0.29$ & $2.02 \pm 0.17$ \\
$\mathbf{4 W}$ & $4.78 \pm 0.64$ & $3.02 \pm 0.24$ & $2.13 \pm 0.21$ \\
\hline
\end{tabular}


Figure 2.3. The percent difference in mass between each exercised group and the control over the 24-week growout period. * Indicates significant difference of that group from the control. ** Used to indicate significant difference of that group from all other groups. 


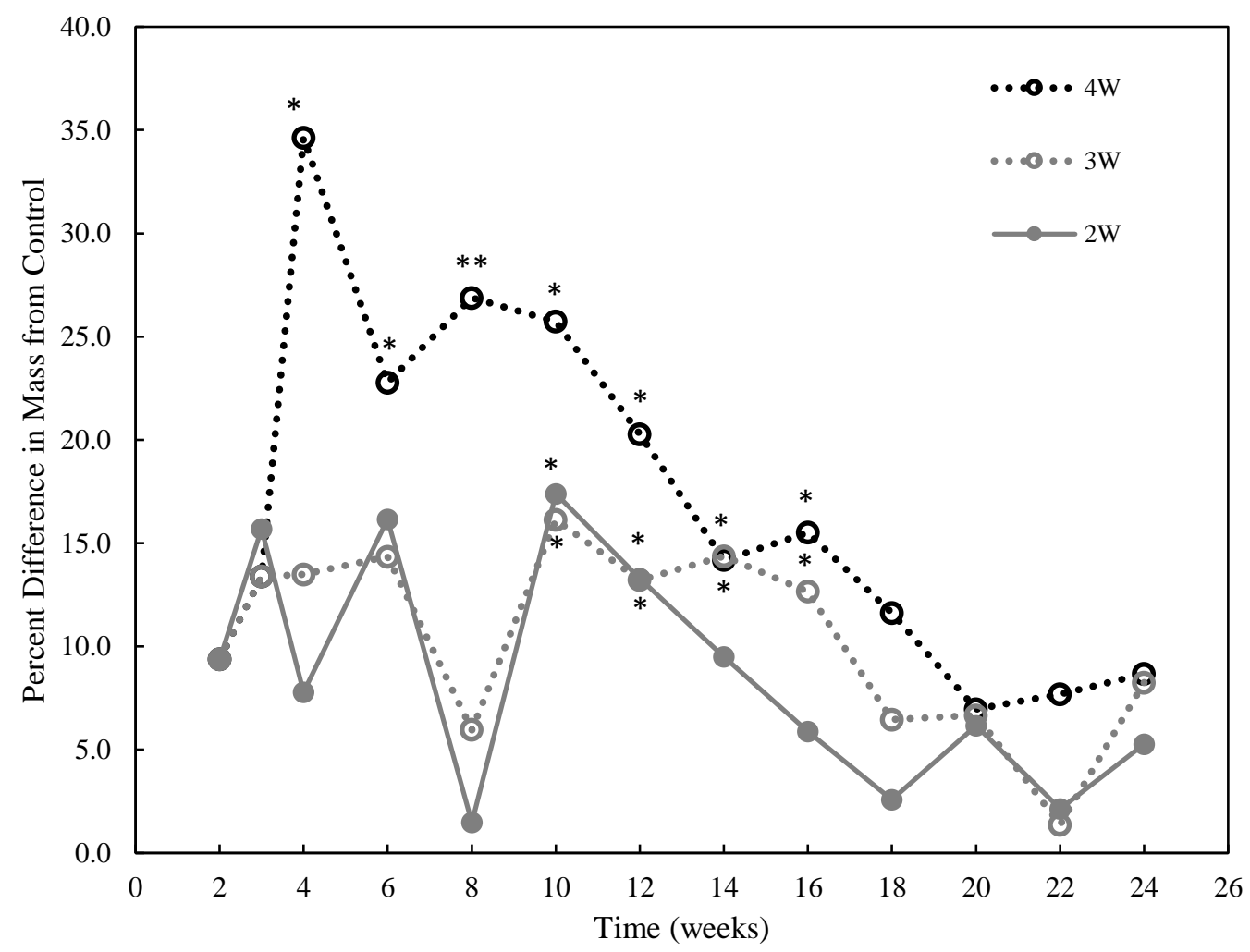


Figure 2.4. Results of the von Bertalanffy growth model fit to fork length data of each experimental group ( $\mathrm{n}=30$ for each group at each time point). 


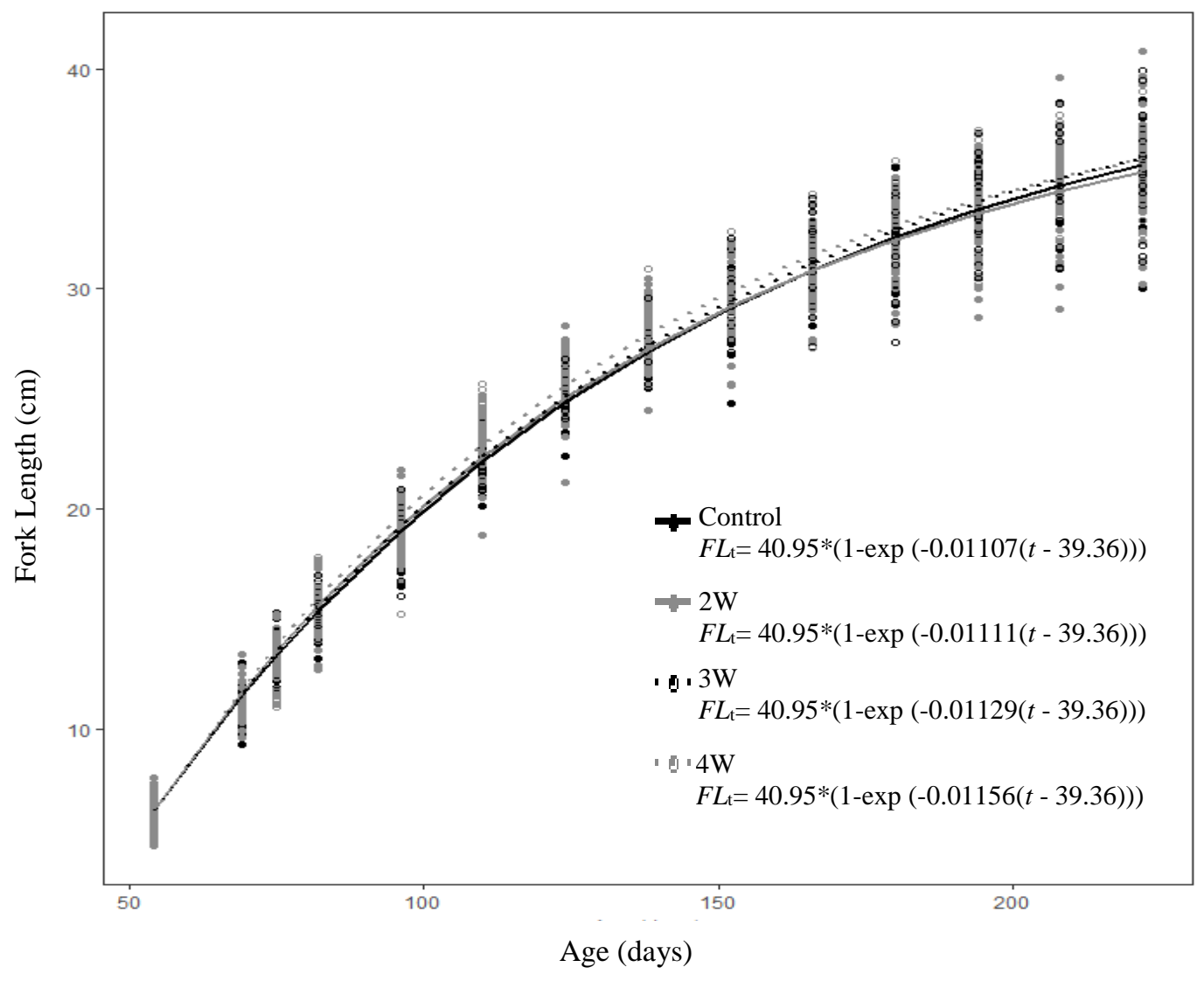


Figure 2.5. Mean standard metabolic rate (SMR) for three exercised groups (2W, $3 \mathrm{~W}$, and $4 \mathrm{~W}$ ) and a control measured at three points during growout (Size A: immediately post-exercise; Size B: approximately six weeks post-exercise; Size C: approximately 12 weeks post-post exercise). For direct comparison between groups, SMR data for individual fish were adjusted to a temperature of $22{ }^{\circ} \mathrm{C}$ using $Q_{10}=2$, and scaled to $55 \mathrm{~g}$ at Size A, $205 \mathrm{~g}$ at Size B, and $410 \mathrm{~g}$ at Size C using mass ${ }^{0.80}$. 


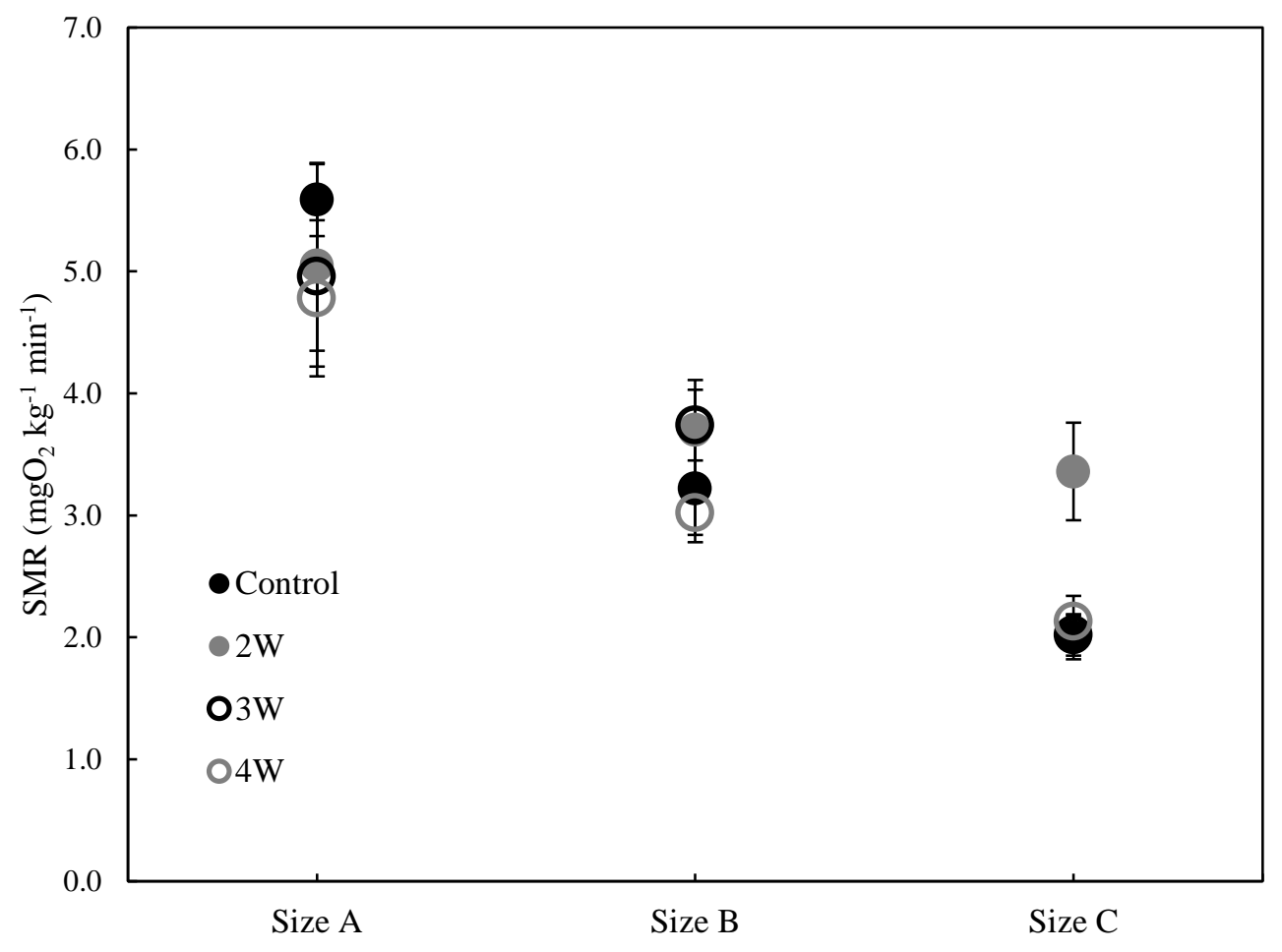




\section{Discussion}

S. dorsalis that swam continuously for two, three, or four weeks at optimal speeds showed improved growth when measured immediately following exercise training, and the group that had the most favorable response $(4 \mathrm{~W})$ retained their statistically significant growth advantage for 12 weeks post exercise.

Additionally, it appears that training provided a slight metabolic advantage to the exercised groups, with SMRs being approximately 10-15\% lower than the controls, but this initial advantage did not persist over the growout period and the exercised groups showed less than a 5\% improvement in FCR.

The observed growth response in the current study measured immediately following each exercise regime was similar in magnitude to those observed in previous studies on $S$. dorsalis and other Seriola species (Table 2.7), with the $2 \mathrm{~W}$, $3 \mathrm{~W}$ and $4 \mathrm{~W}$ fish having approximately $11 \%, 15 \%$, and $38 \%$ increases in growth respectively compared to the controls measured at the same time points. These increases fall within the range observed by Brown et al. (2011) with 10\% greater growth of $S$. lalandi subjected to six weeks of exercise at flows of $0.75 \mathrm{BL} \mathrm{s}^{-1}$, and Palstra et al. (2015) with a $46 \%$ increase in growth for $S$. lalandi exercised for 18 days at optimal speed $\left(2.46 \mathrm{BL} \mathrm{s}^{-1}\right)$, resulting in the exercised fish being approximately $11 \%$ larger than the non-exercised controls (Table 2.7). Additionally, Peters et al. (2009) found that S. dorsalis exercised at $60 \%$ of their critical swimming speed for 34 days, had a 17\% increase in growth. Several other species have demonstrated improvement in growth of a similar magnitude (1040\%) when measured immediately following exercise training (see Davison 1997 
for review) including Arctic Charr (Salvelinus alpinus (Christiansen et al., 1989)), Atlantic Salmon (Salmo salar ((Totland et al., 1987)), Brook Trout (Salvelinus fontinalis (Leon, 1986)), and Striped Bass (Morone saxatilis (Young and Cech Jr, 1993b); however, the effect of exercise on growth appears to be influenced by the exercise regime, including intensity and duration of exercise. Additionally, differences in the diet, temperature, species, and size of fish being tested, make it difficult in many instances for direct comparison of the growth response between studies.

In this study, the $4 \mathrm{~W}$ group demonstrated the most persistent growth response to sustained exercise, retaining a significantly larger mass than the controls for 12 weeks (84 days) post exercise. Additionally, the $3 \mathrm{~W}$ and $2 \mathrm{~W}$ groups were significantly larger than the controls from 6-12 weeks post exercise, and 6-8 weeks post exercise, respectively. These results indicate that a longer duration of exercise training may have a more lasting effect on growth. However, regardless of amount of exercise, the magnitude of the initial growth advantage diminished over time and the exercised fish were only 5-9\% larger than the controls (a non-significant difference) at the end of the 24 week growout period (Figure 2.3). The cause for this decrease in size advantage is unclear, but some of the observed variance in the data between growth measurements could be due to the large size range of the individuals within each group, in tandem with only measuring a subsample of fish from each group at each time point, reducing the ability to determine statistical differences in size between groups. However, this variance would not explain the apparent declining trend in size advantage of the 
exercised fish seen in Figure 2.3. It may be possible that the shape and size of the growout tanks disproportionately affected the larger exercised fish, limiting their growth. Although equal fish densities and environmental parameters were maintained across tanks, the relatively narrow oval shape of the tanks may have made maneuvering slightly more difficult for larger fish and could have impacted swimming efficiency and energy costs, which could also explain why there was not a substantial improvement in the FCR of the exercised groups. Future work should thus consider repeating these experiments with larger round growout tanks (or oceanic pens) to determine if tank or pen size and shape may affect the persistence and magnitude of the growth response over time. The only other study known to the author to examine persistence of a growth response to exercise, showed improvements lasting at least 56 days post-conditioning in young-of-theyear Striped Bass (growth measurements were not conducted beyond that point) (Young and Cech Jr, 1994). Additional work is needed to better understand the long-term effect of sustained exercise on growth.

In the von Bertalanffy model, the Brody growth coefficient $(K)$, is indicative of how fast the fish approaches their asymptotic average maximum length $\left(L_{\infty}\right)$. The AIC scores suggest that the best model fit is one in which the $L_{\infty}$ parameter does not vary across groups, but the $K$ parameter does. A significantly larger $K$, as seen in group $4 \mathrm{~W}$, indicates that those fish were approaching $L_{\infty}$ the fastest. Understanding these growth dynamics could be advantageous for producers in determining time to market size, but being that the model only 
represents growth for approximately the first 220 days of life, it could be further refined with an even longer growout period.

Feed conversion did not appear to be strongly affected by exercise training in this study. Previous work has shown improved FCR after sustained exercise for several species, including Yellowtail Kingfish (Seriola lalandi (Palstra et al., 2015)), the Japanese Amberjack (Seriola quinqueradiata (Yogata et al. 2000)) Gilthead Seabream (Sparus aurata L. (Ibarz et al., 2011)), and Atlantic Salmon (Salmo salar (Herbert et al., 2011)), but limited or even a negative effects for other species (Castro et al., 2011; Jørgensen and Jobling, 1993; Li et al., 2013; Totland et al., 1987). Studies involving Seriola, have shown large variability in FCRs of exercised fish, from 0.62 (Yogata et al. 2000) to 1.89 (Brown et al. 2011) with the FCRs of the exercised fish in the current study (1.16-1.19) falling within that range. In those same studies, reductions in FCR of exercised fish as compared to a control, have varied greatly from $8-32 \%$ (see Table 2.7 for comparison of Seriola spp.). FCR is a difficult metric to compare between studies since it is influenced by several factors including fish size, species, and temperature, which often vary. For example, Árnason et al. (2009) found that in general, feed conversion ratio was lower (more efficient) for smaller sized Turbot (Schophthalmus maximus) at a given temperature than larger Turbot, and also that the optimal temperature for a low FCR changed with fish size. Furthermore, they found that optimal temperature for FCR was different than the optimal temperature for growth, and the relationship of these two variables changed with fish size. In contrast, Handeland et al (2008) found that as Atlantic Salmon grew, 
feed conversion efficiency (the inverse of FCR) generally increased, meaning the fish became more efficient at larger sizes, although the magnitude of the response was also related to temperature. FCR is thus dependent on complex interactions between the fish and its environment, and further studies examining FCR in $S$. dorsalis and how it relates to other variables (e.g., temperature, salinity, exercise, and growth) are necessary for a better understanding of these dynamics and their implications for rearing this species in aquaculture.

In addition to exercise, temperature, and fish size, feeding regime and feed type may also influence FCR and the growth response to exercise. Leon (1986) found that exercised Brook Trout that were fed an equal percentage of body weight as the non-exercised control group had an FCR of 1.49, which was lower than the exercised group fed to satiation (1.54) and the control (1.58). However, the exercised group fed to satiation grew faster and had a significantly greater final mass than the unsatiated exercised fish, which showed no difference in growth from the non-exercised controls (Leon, 1986). As all fish in the current study were fed to satiation, our positive growth response and minimally lower FCRs are consistent with these findings, however it would be of interest to include an unsatiated exercised group in future studies of S. dorsalis to further examine this response.

The lower SMRs of the $2 \mathrm{~W}, 3 \mathrm{~W}$, and $4 \mathrm{~W}$ groups $(9.6 \%, 11.3 \%$, and $14.5 \%$ lower respectively) measured in the week post-exercise were not significantly different from the control, but may have contributed toward the enhanced growth observed following exercise. Similar results were seen in 
exercised S. lalandi from Brown et al. (2011) that had approximately 7\% lower SMRs than non-exercised controls, and although the difference was not significant, a growth improvement of similar magnitude (10\%) was observed Specifically, having reduced energy needs for basic metabolic functions can free up energy for other functions such as growth (Fry, 1947; Warren and Davis, 1967). However, any metabolic advantage seen for the exercised fish in the current study did not seem to be retained post exercise, and this seems to parallel the trend of decreasing metabolic fitness observed for the wild-caught fish in Chapter 2 as they were retained in captivity. If enhanced metabolic fitness could be maintained for a longer duration, it may have a larger effect on FCR and growth over time.

Results of the physiological metrics used in the current study also allow for comparison with previous work to gauge potential effects of improvements in rearing techniques on fitness of hatchery-produced $S$. dorsalis. Table 2.8 shows a comparison of SMR data for several studies using S. dorsalis produced by HubbsSeaWorld Research Institute, which is currently developing culture-rearing methods for this species (Stuart and Drawbridge, 2013). Improvements in larval rearing techniques implemented over the past several years appear to have led to better baseline metabolic fitness of hatchery fish, specifically demonstrated by the approximately 46\% decrease in SMR from 2012 to 2016 (Table 2.8). As discussed in Chapter 2, wild-fish became less metabolically fit with time in a captive environment, which is evidenced by the SMRs of wild-caught fish at three stages of captivity in Table 2.8. However, even wild-fish held in captivity for 
eight months had SMRs $21 \%$ lower than the most fit hatchery cohort, indicating there is still room for further progress in lowering SMRs to reach the level of wild-caught conspecifics, which could further improve feed conversion and growth in captivity.

More research on specific rearing conditions for optimal development is needed for S. dorsalis, and future studies should examine the role of exercise by introducing regimes of varying duration and intensity at different, or even multiple life stages. Although positive growth and FCR results have been seen in Seriola at larger body sizes (Table 2.7), changes to the musculature in the larval stage are often irreversible (Johnston, 2006) so introducing fitness even earlier in development than in the current study could have longer lasting effects. Further research should determine optimal life stage for introducing exercise that leads to sustained periods of fitness and superior growth that could have significant commercial implications. It would also be important to determine the type of muscle growth and development that occurs during exercise training, as the white muscle is the final product of commercial aquaculture. Although several studies have observed white muscle growth in response to sustained exercise training (Totland et al., 1987; Young and Cech Jr, 1993a, 1993b), this has not been specifically examined in S. dorsalis.

\section{Conclusions}

This study showed that the duration of exercise training effects the magnitude and persistence of the growth response, but has little influence on feed 
conversion of $S$. dorsalis fed to satiation. Although not significant, a reduction in SMR by approximately $10-15 \%$ measured immediately following sustained exercise points to potential for optimal exercise conditions to affect metabolism, which may in turn improve growth. Further research is needed to understand the interplay between variables involved in crafting an optimal exercise regime (such as duration and intensity of exercise, temperature, fish size, life stage, and feeding regime), and the subsequent effects on the growth and physiological response of S. dorsalis reared in aquaculture. The potential benefits of exercise training to metabolism, growth, feed conversion and muscle morphology, could have significant commercial implications that warrant further investigation and analysis for this species of interest. 
Table 2.7. Comparison of sustained exercise regimes and subsequent growth and FCR responses for Seriola as measured immediately following exercise. 


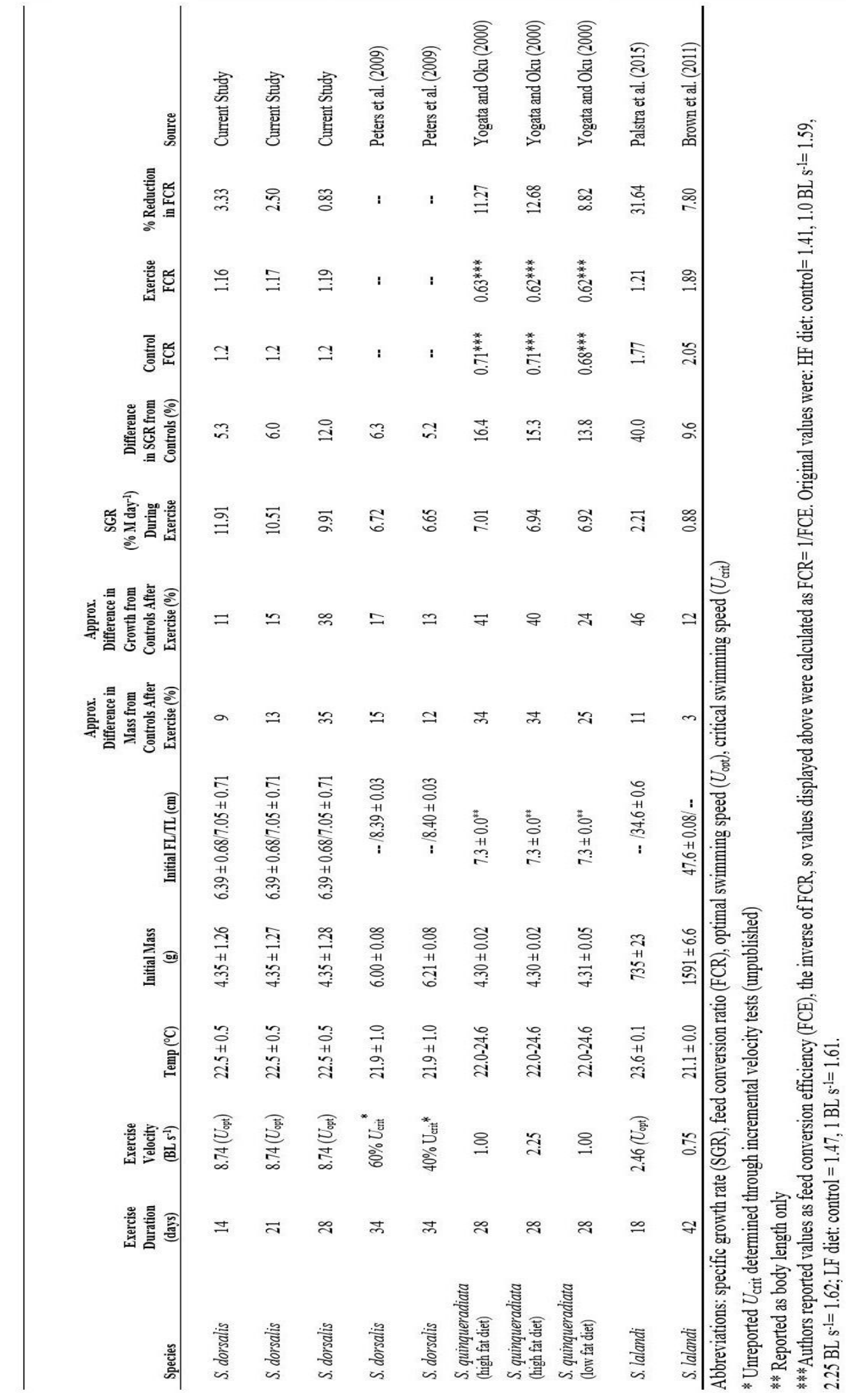


Table 2.8. SMRs of three hatchery-reared cohorts provided by HSWRI compared to a wild "standard." For direct comparison, all SMRs were adjusted to a temperature of $18^{\circ} \mathrm{C}$ using $Q_{10}=2$, and scaled to $65 \mathrm{~g}$ using mass ${ }^{0.80}$ (adjusted SMR). 


\begin{tabular}{lccccl}
\hline Cohort & $\begin{array}{c}\text { Adjusted } \\
\text { SMR } \\
\left(\mathbf{m g O}_{2} \mathbf{~ k g}^{-1} \mathbf{m i n}^{-1}\right)\end{array}$ & $\begin{array}{c}\text { Reported SMR } \\
(\mathbf{m g O 2} \mathbf{~ k g - 1 ~} \mathbf{~ m i n}-\mathbf{1})\end{array}$ & $\begin{array}{c}\text { Mass } \\
(\mathbf{g})\end{array}$ & $\begin{array}{c}\text { Temp } \\
\left.{ }^{\circ} \mathbf{C}\right)\end{array}$ & Source \\
\hline Hatchery 2012 & 7.67 & 7.36 & 80 & 18 & Wegner et al. (in review) \\
Hatchery 2015 & 5.60 & 5.60 & 65 & 18 & Chapter 2 \\
Hatchery 2016 & 5.41 & 5.59 & 55 & 22 & current study \\
$\begin{array}{l}\text { Wild 2015 } \\
(<1 \text { month in captivity) }\end{array}$ & 3.08 & 3.08 & 65 & 18 & Chapter 2 \\
$\begin{array}{l}\text { Wild 2012 } \\
(2-4 \text { months in captivity) }\end{array}$ & 4.14 & 3.97 & 80 & 18 & Wegner et al. (in review) \\
$\begin{array}{l}\text { Wild 2015 } \\
\text { ( 8 months in captivity) }\end{array}$ & 4.27 & 2.95 & 415 & 18 & Chapter 2 \\
\hline
\end{tabular}




\section{REFERENCES}

Adams, C. E., Huntingford, F. A., Krpal, J., Jobling, M., and Burnett, S. J. (1995). Exercise, agonistic behaviour and food acquisition in Arctic charr, Salvelinus alpinus. Environmental Biology of Fishes, 43(2), 213-218.

Árnason, T., Björnsson, B., Steinarsson, A., and Oddgeirsson, M. (2009). Effects of temperature and body weight on growth rate and feed conversion ratio in turbot (Scophthalmus maximus). Aquaculture, 295(3), 218-225.

Arnholt, A.T. (2012). BSDA: Basic Statistics and Data Analysis. R package version 1.01 .

Bagatto, B., Pelster, B., and Burggren, W. W. (2001). Growth and metabolism of larval zebrafish: effects of swim training. The Journal of Experimental Biology, 204(Pt 24), 4335-4343.

Basaran, F., Ozbilgin, H., and Ozbilgin, Y. D. (2007). Comparison of the swimming performance of farmed and wild gilthead sea bream, Sparus aurata. Aquaculture Research, 38(5), 452-456.

Battaglene, S., and Talbot, R. (1992). Induced spawning and larval rearing of snapper, Pagrus auratus (Pisces: Sparidae), from Australian waters. New Zealand journal of marine and freshwater research, 26(2), 179-185.

Baty, F., Ritz, C., Charles, S., Brutsche, M., Flandrois, J.-P., and Delignette Muller, M.-L. (2015). A Toolbox for Nonlinear Regression in R: The Package nlstools. Journal of Statistical Software, 66(5), 1-21.

Baxter, J. L. (1960). Fish Bulletin No. 110. A Study of The Yellowtail Seriola Dorsalis (Gill).

Bell, W. H., and Terhune, L. D. B. (1970). Water Tunnel Design for Fisheries Research. Canada.

Bone, Q., Kiceniuk, J., and Jones, D. R. (1978). On the role of the different fibre types in fish myotomes at intermediate swimming speeds. NOAA Fishery Bulletin, 76(3), 691-699.

Bone, Q., Marshall, N. B., and Blaxter, J. H. S. (1995). Buoyancy. Biology of Fishes (pp. 79-95). New York, NY: Blackie Academic and Professional. 
Brett, J. R. (1964). The Respiratory Metabolism and Swimming Performance of Young Sockeye Salmon. Journal of the Fisheries Research Board of Canada, 21(5), 1183-1226.

Brett, J. R., and Groves, T. D. D. (1979). Physiological Energetics. In W. S. Hoar, D. J. Randall, \& J. R. Brett (Eds.), Fish Physiology (Vol. VIII, pp. 279352). San Francisco: Academic Press.

Brix, O. (2002). The Physiology of Living in Water. In P. J. B. Hart \& J. D. Reynolds (Eds.), Handbook of Fish BIology and Fisheries (Vol. 1, pp. 7196): Blackwell Science Ltd.

Brown, E. J., Bruce, M., Pether, S., and Herbert, N. A. (2011). Do swimming fish always grow fast? Investigating the magnitude and physiological basis of exercise-induced growth in juvenile New Zealand yellowtail kingfish, Seriola lalandi Fish Physiol Biochem, 37(2), 327-336.

Burnham, K.P., and Anderson, D.R. (2002). Model selection and multimodel inference: a practical information-theoretic approach (Second ed.). New York, NY: Springer-Verlag.

Castro, V., Grisdale-Helland, B., Helland, S. J., Kristensen, T., Jørgensen, S. M., Helgerud, J., . . . Takle, H. (2011). Aerobic training stimulates growth and promotes disease resistance in Atlanticsalmon (Salmo salar). Comparative Biochemistry and Physiology, Part A, 160, 278-290.

Chatain, B. (1989). Problems related to the lack of functional swimbladder in intensive rearing of Dicentrarchus labrax and Sparus auratus. Advances in Tropical Aquaculture, 9, 699-709.

Chatain, B. (1994). Abnormal swimbladder development and lordosis in sea bass (Dicentrarchus labrax) and sea bream (Sparus auratus). Aquaculture, 119(4), 371-379.

Christiansen, J. S., and Jobling, M. (1990). The behaviour and the relationship between food intake and growth of juvenile Arctic charr, Salvelinus alpinus L., subjected to sustained exercise. Canadian Journal of Zoology, 68(10), 2185-2191.

Christiansen, J. S., Ring $\varnothing$, E., and Jobling, M. (1989). Effects of sustained exercise on growth and body composition of first-feeding fry of Arctic charr, Salvelinus alpinus (L.). Aquaculture, 79(1), 329-335. 
Christiansen, J. S., Svendsen, Y. S., and Jobling, M. (1992). The combined effects of stocking density and sustained exercise on the behaviour, food intake, and growth of juvenile Arctic charr (Salvelinus alpinus L.). Canadian Journal of Zoology, 70(1), 115-122.

Collins, R. A. (1973). The Status of The California Yellowtail Resource and its Management: California Department of Fish and Game.

Colt, J. (2006). Water quality requirements for reuse systems. Aquacultural Engineering, 34(3), 143-156.

Czesny, S. J., Graeb, B. D. S., and Dettmers, J. M. (2005). Ecological Consequences of Swim Bladder Noninflation for Larval Yellow Perch. Transactions of the American Fisheries Society, 134(4), 1011-1020.

Davison, W. (1997). The Effects of Exercise Training on Teleost Fish, a Review of Recent Literature. Comparative Biochemistry and Physiology Part A: Physiology, 117(1), 67-75.

Davison, W., and Goldspink, G. (1977). The Effect of Prolonged Exercise on the Lateral Musculature of the Brown Trout (Salmo trutta). Journal of Experimental Biology, 70(1), 1-12.

Duthie, G. G. (1987). Observations of poor swimming performance among hatchery-reared rainbow trout, Salmo gairdneri. Environmental Biology of Fishes, 18(4), 309-311.

East, P., and Magnan, P. (1987). The effect of locomotor activity on the growth of brook charr, Salvelinus fontinalis Mitchill. Canadian Journal of Zoology, 65(4), 843-846.

FAO. (2014). The State of World Fisheries and Aquaculture: United Nations. Rome.

FAO. (2016). The State of World Fisheries and Aquaculture United Nations. Rome.

Fry, F. E. J. (1947). Effects of the Environment on Animal Activity: University of Toronto Press.

Hammenstig, D., Sandblom, E., Axelsson, M., and Johnsson, J. I. (2014). Effects of rearing density and dietary fat content on burst-swim performance and 
oxygen transport capacity in juvenile Atlantic salmon Salmo salar. Journal of Fish Biology, 85(4), 1177-1191.

Handeland, S. O., Imsland, A. K., and Stefansson, S. O. (2008). The effect of temperature and fish size on growth, feed intake, food conversion efficiency and stomach evacuation rate of Atlantic salmon post-smolts. Aquaculture, 283(1), 36-42.

Hashimoto, H., Imai, A., Iwasaki, T., Hamasaki, K., Teruya, K., Hamada, K., and Mushiake, K. (2012). Feeding and Growth of Larval Greater Amberjack Seriola dumerili with Non-inflated, Normal Inflated and Over-inflated Swim Bladders. Aquaculture Science, 60(1), 99-106.

Herbert, N. A., Kadri, S., and Huntingford, F. A. (2011). A moving light stimulus elicits a sustained swimming response in farmed Atlantic salmon, Salmo salar L. Fish Physiology and Biochemistry, 37(2), 317-325.

Hudson, R. C. L. (1973). On the function of the white muscles in teleosts at intermediate swimming speeds. Journal of Experimental Biology, 58(2), 509-522.

Ibarz, A., Felip, O., Fernández-Borràs, J., Martín-Pérez, M., Blasco, J., and Torrella, J. R. (2011). Sustained swimming improves muscle growth and cellularity in gilthead sea bream. Journal of Comparative Physiology B, 181(2), 209-217.

Jacquemond, F. (2004a). Separated breeding of perch fingerlings (Perca fluviatilis L.) with and without initial inflated swim bladder: comparison of swim bladder development, skeleton conformation and growth performances. Aquaculture, 239(1-4), 261-273.

Jacquemond, F. (2004b). Sorting Eurasian perch fingerlings (Perca fluviatilis L.) with and without functional swim bladder using tricaine methane sulfonate. Aquaculture, 231(1-4), 249-262.

James, K. (2014). Monterey Bay Aquarium Seafood Watch: California yellowtail, White seabass.

Johnston, I. A. (1999). Muscle development and growth: potential implications for flesh quality in fish. 177(Issues 1-4), 99-115. 
Johnston, I. A. (2006). Environment and plasticity of myogenesis in teleost fish. Journal of Experimental Biology, 209(12), 2249-2264.

Johnston, I. A., and Moon, T. W. (1979). Endurance exercise training in the fast and slow muscles of a teleost (Pollachius virens). Journal of Comparative Physiology, 135(2), 147-156.

Johnston, I. A., and Moon, T. W. (1980). Exercise Training in Skeletal Muscle of Brook Trout (<em >Salvelinus Fontinalis $</ \mathrm{em}>)$. The Journal of Experimental Biology, 87(1), 177-194.

Jørgensen, E. H., and Jobling, M. (1993). The effects of exercise on growth, food utilisation and osmoregulatory capacity of juvenile Atlantic salmon, Salmo salar. Aquaculture, 116(2-3), 233-246.

Kindschi, G. A., and Barrows, F. T. (1993). Survey of Swim Bladder Inflation in Walleyes Reared in Hatchery Production Ponds. The Progressive FishCulturist, 55(4), 219-223.

Kurata, M., Ishibashi, Y., Seoka, M., Honryo, T., Katayama, S., Fukuda, H., . . . Sawada, Y. (2015). Influence of swimbladder inflation failure on mortality, growth and lordotic deformity in Pacific bluefin tuna, Thunnus orientalis, (Temminck \& Schlegel) postflexion larvae and juveniles. Aquaculture Research, 46(6), 1469-1479.

Le François, N. R., Lemieux, H., and Blier, P. U. (2002). Biological and technical evaluation of the potential of marine and anadromous fish species for cold-water mariculture. Aquaculture Research, 33(2), 95-108.

Leon, K. A. (1986). Effect of Exercise on Feed Consumption, Growth, Food Conversion, and Stamina of Brook Trout. The Progressive Fish-Culturist, 48(1), 43-46.

Li, X.-M., Yu, L.-J., Wang, C., Zeng, L.-Q., Cao, Z.-D., Fu, S.-J., and Zhang, Y.G. (2013). The effect of aerobic exercise training on growth performance, digestive enzyme activities and postprandial metabolic response in juvenile qingbo (Spinibarbus sinensis). Comparative Biochemistry and Physiology Part A: Molecular \& Integrative Physiology, 166(1), 8-16.

Martinez-Takeshita, N., Purcell, C. M., Chabot, C. L., Craig, M. T., Paterson, C. N., Hyde, J. R., and Allen, L. G. (2015). A Tale of Three Tails: Cryptic 
Speciation in a Globally Distributed Marine Fish of the Genus Seriola. Copeia, 103(2), 357-368.

Marty, G. D., Hinton, D. E., and Summerfelt, R. C. (1995). Histopathology of swimbladder noninflation in walleye (Stizostedion vitreum) larvae: role of development and inflammation. Aquaculture, 138(1), 35-48.

McDonald, D. G., Milligan, C. L., McFarlane, W. J., Croke, S., Currie, S., Hooke, B., .. . Davidson, K. (1998). Condition and performance of juvenile Atlantic salmon (Salmo salar): effects of rearing practices on hatchery fish and comparison with wild fish. Canadian Journal of Fisheries and Aquatic Sciences, 55(5), 1208-1219.

Moran, D., Smith, C. K., Gara, B., and Poortenaar, C. W. (2007). Reproductive behaviour and early development in yellowtail kingfish (Seriola lalandi Valenciennes 1833). Aquaculture, 262(1), 95-104.

Nakada, M. (2002). Yellowtail Culture Development and Solutions for the Future. Reviews in Fisheries Science, 10(3/4), 559.

Nakada, M. (2008). Capture-based aquaculture of yellowtail. Rome.

Ogata, T., and Mori, M. (1964). Histochemical study of oxidative enzymes in vertebrate muscles. Journal of Histochemistry \& Cytochemistry, 12(3), 171-182.

Ogle, D. (2013). FishR Vignette- Von Bertalanffy Growth Models. http://derekogle.com/fishR/examples/oldFishRVignettes/VonBertalanffy.p df

Ogle, D.H. (2017). FSA: Fisheries Stock Analysis. R package version 0.8.13.

Ogle, D.H. (2017). FSAdata: Fisheries Stock Analysis, Datasets. R package version 0.3.6.

Palstra, A. P., Mes, D., Kusters, K., Roques, J. A., Flik, G., Kloet, K., and Blonk, R. J. W. (2015). Forced sustained swimming exercise at optimal speed enhances growth of juvenile yellowtail kingfish (Seriola lalandi). Frontiers in Physiology, 5, 506.

Palstra, A. P., and Planas, J. V. (2011). Fish under exercise. Fish Physiology and Biochemistry, 37(2), 259-272. 
Pedersen, L. F., Koed, A., and Malte, H. (2008). Swimming performance of wild and F1-hatchery-reared Atlantic salmon (Salmo salar) and brown trout (Salmo trutta) smolts. Ecology of Freshwater Fish, 17(3), 425-431.

Pelster, B. (1997). 5 Buoyancy At Depth. In J. R. David \& P. F. Anthony (Eds.), Fish Physiology (Vol. Volume 16, pp. 195-237): Academic Press.

Peters, C. (2009). Continuous Exercise Enhances Swim Performance and Alters Growth Rate, IGF-I, and Cortisol in Juvenile Marine Finfish in Aquaculture. (Masters of Science in Marine Science), University of San Diego, San Diego, CA.

Pirozzi, I., and Booth, M. A. (2009). The routine metabolic rate of mulloway (Argyrosomus japonicus: Sciaenidae) and yellowtail kingfish (Seriola lalandi: Carangidae) acclimated to six different temperatures. Comp Biochem Physiol A Mol Integr Physiol, 152(4), 586-592.

Prestinicola, L., Boglione, C., and Cataudella, S. (2014). Relationship between uninflated swim bladder and skeletal anomalies in reared gilthead seabream (Sparus aurata). Aquaculture, 432, 462-469.

Rezende, E. L., Gomes, F. R., Ghalambor, C. K., Russell, G. A., and Chappell, M. A. (2005). An evolutionary frame of work to study physiological adaptation to high altitudes. Revista chilena de historia natural, 78, 323336.

Ricker, W. E. (1975). Computation and Interpretation of Biological Statistics of Fish Populations. Bulletin of the Fisheries Research Board of Canada, $191,1-382$.

Sala, E., Aburto-Oropeza, O., Paredes, G., and Thompson, G. (2003). Spawning aggregations and reproductive behavior of reef fishes in the Gulf of California. Bulletin of Marine Science, 72(1), 103-121.

Sepulveda, C. A., Dickson, K. A., and Graham, J. B. (2003). Swimming performance studies on the eastern Pacific bonito Sarda chiliensis, a close relative of the tunas (family Scombridae) I. Energetics. The Journal of Experimental Biology, 206, 2739-2748.

Shustov, Y. A., and Shchurov, I. L. (1988). Quantitative estimation of stamina of wild and hatchery-reared Atlantic salmon (Salmo salar L.). Aquaculture, 71(1), 81-87. 
Skov, P. V., Larsen, B. K., Frisk, M., and Jokumsen, A. (2011). Effects of rearing density and water current on the respiratory physiology and haematology in rainbow trout, Oncorhynchus mykiss at high temperature. Aquaculture, 319(3), 446-452.

Spicer, J. I., and Burggren, W. W. (2003). Development of physiological regulatory systems: altering the timing of crucial events. Zoology (Jena), 106(2), 91-99.

Steen, J. B. (1970). The Swim Bladder as a Hydrostatic Organ. In W. S. Hoar \& D. J. Randall (Eds.), Fish Physiology (Vol. IV, pp. 413-443). New York, NY: Academic Press, Inc. .

Stuart, K. R., and Drawbridge, M. A. (2013). Captive spawning and larval rearing of California yellowtail (Seriola lalandi). 44(5), 728-737.

Totland, G. K., Kryvi, H., Jødestøl, K. A., Christiansen, E. N., Tangerås, A., and Slinde, E. (1987). Growth and composition of the swimming muscle of adult Atlantic salmon (Salmo salar L.) during long-term sustained swimming. Aquaculture, 66(3), 299-313.

Trotter, A. J., Pankhurst, P. M., and Hart, P. R. (2001). Swim bladder malformation in hatchery-reared striped trumpeter Latris lineata (Latridae). Aquaculture, 198(1-2), 41-54.

Walker, M. G., and Emerson, L. (1978). Sustained swimming speeds and myotomal muscle function in the trout, Salmo gairdneri. Journal of Fish Biology, 13(4), 475-481.

Warren, C. E., and Davis, G. E. (1967). Laboratory studies on the feeding, bioenergetics, and growth of fish: Oregon State University. Corvalis, OR.

Webb, P. W. (1998). Swimming. In D. H. Evans (Ed.), The Physiology of Fishes (Second Edition ed., pp. 3-20): CRC Press LLC.

Wegner, N. C., Drawbridge, M. A., and Hyde, J. R. (in review). Reduced swimming and metabolic fitness of aquaculture-reared California Yellowtail (Seriola dorsalis) in comparison to wild-caught fish. Aquaculture.

Woolley, L. D., Fielder, D. S., and Qin, J. G. (2014). Swimbladder inflation, growth and survival of yellowtail kingfish Seriola lalandi (Valenciennes, 
1833) larvae under different temperature, light and oxygen conditions. Aquaculture Research, 45(9), 1489-1498.

Woolley, L. D., Fielder, S. D., and Qin, J. G. (2013). Swimbladder inflation associated with body density change and larval survival in southern bluefin tuna Thunnus maccoyii. Aquaculture International, 21(6), 12331242.

Woolley, L. D., and Qin, J. G. (2010). Swimbladder inflation and its implication to the culture of marine finfish larvae. Reviews in Aquaculture, 2(4), 181190.

Woolley, L. D., and Qin, J. G. (2013). Ontogeny of body density and the swimbladder in yellowtail kingfish Seriola lalandi larvae. Journal of Fish Biology, 82(2), 658-670.

Yang, S. G., Hur, S. W., Ji, S. C., Lim, S. G., Kim, B. S., Jeong, M., . . Lee, Y.D. (2016). Morphological Development of Embryo, Larvae and Juvenile in Yellowtail Kingfish, Seriola lalandi. Development \& Reproduction, 20(2), 131-140.

Yogata, H., and Oku, H. (2000). The effects of swimming exercise on growth and whole-body protein and fat contents of fed and unfed fingerling yellowtail. Fisheries Science, 66(6), 1100.

Young, P. S., and Cech Jr, J. J. (1993a). Effects of Exercise Conditioning on Stress Responses and Recovery in Cultured and Wild Young-of-the-Year Striped Bass, Morone saxatilis. Canadian Journal of Fisheries and Aquatic Sciences, 50(10), 2094-2099.

Young, P. S., and Cech Jr, J. J. (1993b). Improved Growth, Swimming Performance, and Muscular Development in Exercise-Conditioned Young-of-the-Year Striped Bass (Morone saxatilis). Canadian Journal of Fisheries and Aquatic Sciences, 50(4), 703-707.

Young, P. S., and Cech Jr, J. J. (1994). Optimum Exercise Conditioning Velocity for Growth, Muscular Development, and Swimming Performance in Young-of-the-Year Striped Bass (Morone saxatilis). Canadian Journal of Fisheries and Aquatic Sciences, 51(7), 1519-1527. 